\title{
3D FEM Analysis of Pounding Response of Bridge Structures at a Canyon Site to Spatially Varying Ground Motions
}

\author{
Kaiming $\mathrm{Bi}^{1}, *$, Hong $\mathrm{Hao}^{1}$ and Nawawi Chouw ${ }^{2}$ \\ ${ }^{1}$ School of Civil and Resource Engineering, the University of Western Australia, WA 6009, Australia \\ ${ }^{2}$ Department of Civil and Environmental Engineering, the University of Auckland, Auckland 1142, New Zealand
}

(Received: 25 November 2011; Received revised form: 9 May 2012; Accepted: 12 September 2012)

\begin{abstract}
Previous studies of pounding responses of adjacent bridge structures under seismic excitation were usually based on the simplified lumped mass model or beamcolumn element model. Consequently, only 1D point to point pounding, which is usually in the longitudinal direction of the bridge, could be considered. In reality, pounding could occur along the entire surfaces of the adjacent bridge structures. Moreover, spatially varying transverse ground motions generate torsional responses of bridge decks and these responses may cause eccentric poundings. That is why many pounding damages occurred at corners of the adjacent decks as observed in almost all previous major earthquakes. A simplified 1D model cannot capture torsional response and eccentric poundings. To more realistically investigate pounding between adjacent bridge structures, a two-span simply-supported bridge structure located at a canyon site is established with a detailed 3D finite element model in the present study. Spatially varying ground motions in the longitudinal, transverse and vertical directions at the bridge supports are stochastically simulated as inputs in the analysis. The pounding responses of the bridge structure under multi-component spatially varying ground motions are investigated in detail by using the finite element code LS-DYNA. Numerical results show that the detailed 3D finite element model clearly captures the eccentric poundings of bridge decks, which may induce local damage around the corners of bridge decks. It demonstrates the necessity of detailed 3D modelling for a more realistic simulation of pounding responses of adjacent bridge decks to earthquake excitations.
\end{abstract}

Key words: pounding response, eccentric pounding, torsional response, 3D FEM, local site effect, spatially varying ground motions.

\section{INTRODUCTION}

For bridge structures with conventional expansion joints, a complete avoidance of pounding between bridge decks during strong earthquakes is often impossible since the separation gap of an expansion joint is usually a few centimetres to ensure a smooth traffic flow. Therefore, pounding damages of adjacent bridge structures have always been observed in previous major earthquakes. In the 1971 San Fernando earthquake, it was found that impacts between bridge decks and abutments were the source of extensive damages to highway bridges with seat type abutments (Jennings 1971). In the 1989 Loma Prieta earthquake, poundings between the lower roadway and columns supporting the upper-level deck of the Southern viaduct section at the China Basin in California led to significant damage to the decks and column sides (Priestley et al. 1996). Reconnaissance reports from the 1995 Kobe earthquake identified pounding as a major cause of fracture of bearing supports, which subsequently led to the unseating of bridge decks (Kawashima and 
Unjoh 1996). Surveys conducted after the 1999 Chi-Chi Taiwan earthquake revealed that 30 bridges suffered some damages due to poundings at the expansion joints (EERI 1999). Poundings between adjacent bridge structures were also observed in the more recent 2008 Wenchuan earthquake (Lin et al. 2008) and 2011 Christchurch earthquake (Chouw and Hao 2011).

The most straightforward approach to avoid seismic pounding is to provide sufficient separation distances between adjacent structures. Previous studies on the required separation distances to avoid seismic pounding between adjacent structures mainly focused on buildings. Studies on the adjacent bridge structures are relatively less, probably because with conventional expansion joints it is not possible to provide sufficient separations between bridge decks while not affecting the smooth traffic flow as mentioned above. However, with the recent development of modular expansion joint (MEJ) in bridge engineering, the separation gap can be sufficiently large, which makes avoiding pounding possible. Hao (1998) analysed the effect of various bridge and ground motion parameters on the relative displacement between adjacent bridge decks, and defined the required seating length for bridge decks to prevent unseating. Chouw and Hao (2008a) studied the influence of soil-structure interaction (SSI) and ground motion spatial variation effects on the required separation distance of two adjacent bridge frames connected by a MEJ. More recently, Bi et al. investigated local site effect (2010a) and SSI (2011) on the required separation distances between bridge structures crossing a canyon site to avoid seismic pounding.

Pounding is an extremely complex phenomenon involving damage due to plastic deformation, local cracking or crushing, fracturing due to impact, and friction when two adjacent bridge decks are in contact with each other. To simplify the analysis, many researchers modelled a bridge girder as a lumped mass. For example, Malhotra (1998) investigated a concrete bridge that experienced significant pounding during California earthquakes with a lumped mass model; Jankowski et al. (1998) presented an analysis of pounding between superstructure segments of an isolated elevated bridge induced by the seismic wave passage effect; Ruangrassamee and Kawashima (2001) calculated the relative displacement spectra of two single-degree-of-freedom (SDOF) systems with pounding effect; DesRoches and Muthukumar (2002) examined the factors affecting the global response of a multiple-frame bridge due to pounding of adjacent frames; Chouw and Hao (2005, 2008b) studied the influence of ground motion spatial variation and SSI on the relative response of two bridge frames. Some other researchers modelled the bridge girders as beamcolumn elements. For example, Jankowski et al. (2000) discretized the superstructure segments and piers as 3D elastic beam-column elements, and investigated several approaches for reducing the negative effects of pounding between superstructure segments of an isolated elevated bridge. Chouw et al. (2006) modelled the girders and piers as 2D beam elements, and studied the effect of multi-sided poundings on structural responses due to spatially varying ground motions.

Based on these simplified lumped mass model or beam-column element model, only $1 \mathrm{D}$ point to point pounding, usually in the bridge longitudinal axis, can be considered. In a real bridge structure under seismic loading, pounding could take place along the entire surfaces of the adjacent structures. Moreover, it was observed from previous earthquakes that most poundings actually occurred at corners of adjacent bridge decks as shown in Figure 1. This is because torsional responses of the adjacent decks induced by
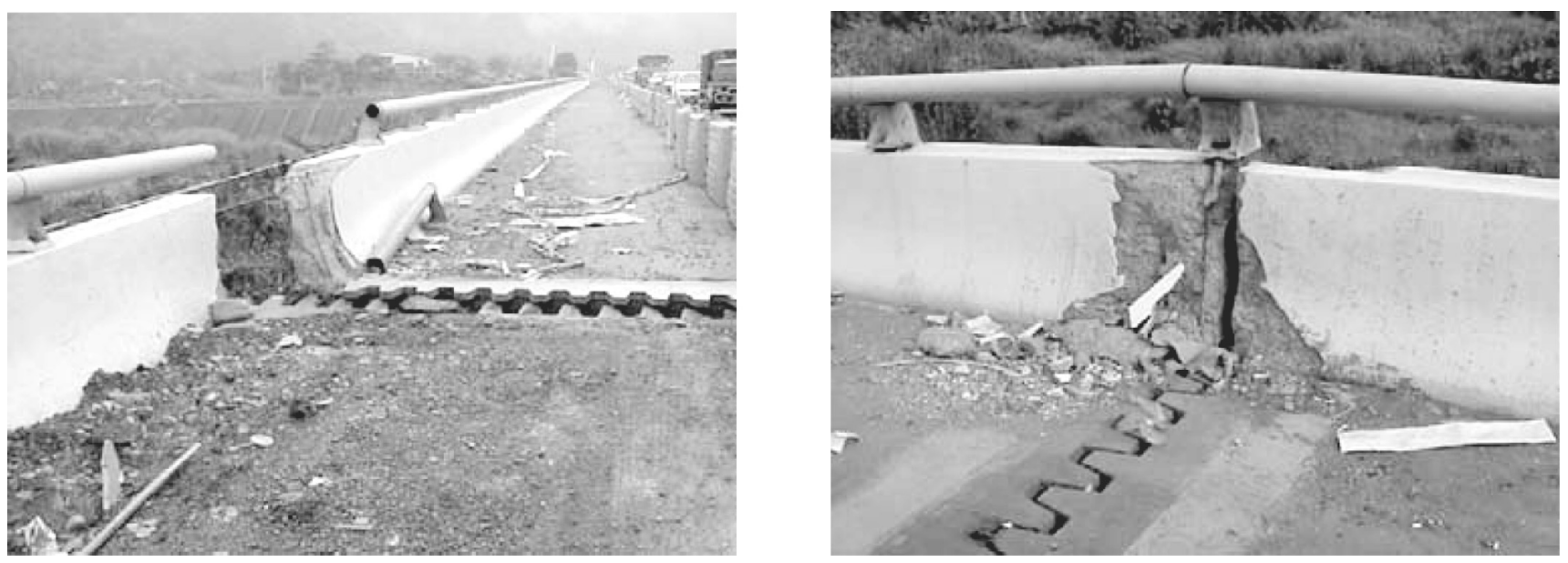

Figure 1. Typical pounding damage between bridge decks in Chi-Chi earthquake 
spatially varying transverse ground motions at multiple bridge supports resulted in eccentric poundings. To more realistically model the pounding phenomenon between adjacent bridge structures, a detailed 3D finite element analysis is necessary. Zanardo et al. (2002) modelled the box-section bridge girders as shell elements and piers as beam-column elements, and carried out a parametric study of pounding phenomenon of a multi-span simplysupported bridge with base isolation devices. Julian et al. (2006) evaluated the effectiveness of cable restrainers to mitigate earthquake damage through connections between isolated and non-isolated sections of curved steel viaducts using three-dimensional non-linear finite element response analysis. Although 3D FE models of bridge structures were developed in those two studies (Zanardo et al. 2002; Julian et al. 2006), neither the surface to surface nor eccentric pounding was considered, instead the pounding was simulated by the contact elements which linked the external nodes of adjacent segments together. Zhu et al. (2002) proposed a 3D contact-friction model to analyse pounding between bridge girders of a three-span steel bridge. This method overcomes the limitation of the previous studies that predefine the pounding locations, and thus provides a more realistic modelling of pounding responses between bridge decks. The drawback of the method is that it could not model material non-linearities during contacts. The task to search contact pairs is also very time consuming and the searching algorithm is complicated. More recently, Jankowski (2009) analyzed the earthquakeinduced pounding between the main building and the stairway tower of the Olive View Hospital based on the non-linear finite element method (FEM), and concluded that the use of FEM with a detailed representation of the geometry and the non-linear material behaviour makes the study of earthquake-induced pounding more reliable than using the discrete lumped mass or beam-column element models. To the best knowledge of the authors, a simultaneous study of surface to surface and torsional response induced eccentric pounding between adjacent bridge structures based on a detailed 3D FEM has not been reported yet.

Pounding between adjacent bridge decks occurs because of large relative displacement responses. Ground motion spatial variation, besides differences in vibration properties of adjacent bridge structures, is a source of relative displacement responses. Owing to the difficulty in modelling ground motion spatial variation, many studies assumed uniform excitations (Malhotra 1998; Ruangrassamee and Kawashima 2001; DesRoches and Muthukumar 2002; Julian 2006; Zhu et al. 2002; Jankowski 2009) or assumed variation was caused by wave passage effect only (Jankowski et al. 1998, 2000).
Only a few studies considered the combined wave passage effect and coherency loss effect in analyzing relative displacement responses of adjacent bridge structures (Chouw and Hao 2005, 2008b; Chouw et al. 2006; Zanardo et al. 2002). It should be noted that all these studies mentioned above assumed that the analyzed structures locate on a flat-lying site, the influence of local soil conditions, which further intensifies ground motion spatial variation at multiple structural supports, was neglected. Studies revealed that local site effect not only causes further phase difference (Der Kiureghian 1996), but also affects the coherency loss between spatial ground motions (Bi and Hao 2011). These differences will significantly affect the structural responses (Bi et al. 2010a, b, 2011). Consequently, neglecting local soil effect on the spatial ground motion variations at multiple supports of a bridge structure crossing a canyon site may lead to inaccurate estimation of bridge responses.

In this study, pounding responses between the abutment and the adjacent bridge deck and between two adjacent bridge decks of a two-span simply-supported bridge located on a canyon site are investigated. A detailed 3D finite element model of the bridge is constructed in ANSYS (2009), and then LS-DYNA (2007) is employed to calculate the structural responses. To model the local site effect on spatial ground motions, the base rock motions are assumed consisting of out-ofplane and in-plane waves and are modelled by a filtered Tajimi-Kanai power spectral density function and an empirical coherency loss function. Seismic waves then propagate vertically through local soil sites to ground surface. The three-dimensional spatially varying ground motions at different supports of the bridge structure are then stochastically simulated based on the combined spectral representation method and the one dimensional wave propagation theory. The simulated spatial ground motions are used as inputs to calculate structural responses. The influences of pounding, local soil condition and ground motion spatial variation effect on the structural responses are investigated in detail. It should be noted that the present study concentrates on modelling the surface to surface pounding and torsional response induced eccentric pounding. To limit the influence factors, the material and bearing non-linearities, pounding induced local damage and soil-structure interaction (SSI) are not considered in the present study, which will be included in the subsequent studies.

\section{METHOD VALIDATION}

To investigate the reliability of using LS-DYNA to simulate the pounding responses, a multi-span concrete bridge studied by Malhotra (1998) is re-examined. The results obtained from the 3D model by using LS-DYNA 
are compared with those of the traditional lumped mass model and beam-column element model by using the contact element to simulate the pounding effect.

Malhotra (1998) studied the collinear impact between two concrete rods based on the stereomechanic method, and then applied the procedure to the analysis of pounding effect of a $300 \mathrm{~m}$ multi-span concrete bridge separated by an intermediate hinge. The bridge was simplified as two uncoupled SDOF systems as shown in Figure 2(a). The length, mass, column stiffness and damping ratio for the short span are $L_{s}=100 \mathrm{~m}, m_{s}=1.2 \times 10^{6} \mathrm{~kg}, k_{s}=$ $107 \mathrm{MN} / \mathrm{m}$ and $\xi_{s}=0.05$, respectively. The corresponding parameters for the long span are $L_{l}=200 \mathrm{~m}, m_{l}=2.4 \times$ $10^{6} \mathrm{~kg}, k_{l}=94 \mathrm{MN} / \mathrm{m}$ and $\xi_{l}=0.05$. These parameters correspond to the vibration frequencies for the short and long span of $f_{s}=1.5$ and $f_{l}=0.996 \mathrm{~Hz}$, respectively (Malhotra 1998). The separation gap is $5 \mathrm{~cm}$.

Using the stereomechanic method, the parameters given above are enough. However, for the beam-column element model and 3D finite element model, these parameters are insufficient. Therefore, the following parameters are also used based on the known properties of the bridge. They are: Young's modulus of the bridge decks and piers $E=35 \mathrm{GPa}$; density $\rho=2400 \mathrm{~kg} / \mathrm{m}^{3}$; rectangular cross section of the decks $2 \times 2.5 \mathrm{~m}$ with

(a)

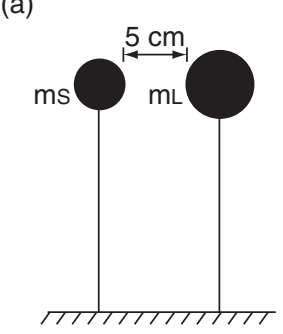

(b)

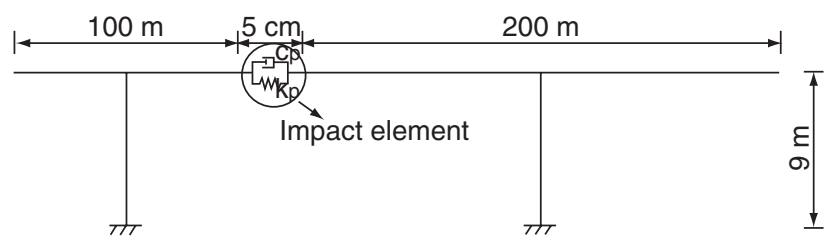

(c)

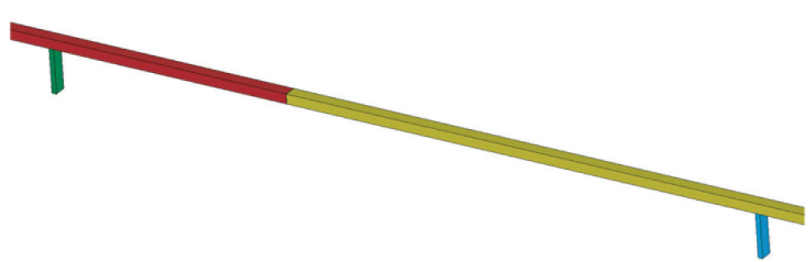

Figure 2. Different models (not to scale): (a) lumped mass model (after Malhotra 1998); (b) beam column element model; and (c) 3D finite element model
$2.5 \mathrm{~m}$ in the transverse direction of the bridge; heights of the bridge piers $h=9 \mathrm{~m}$, with cross section $0.963 \times$ $2.5 \mathrm{~m}$ and $0.922 \times 2.5 \mathrm{~m}$ for the short and long span, respectively. Figures 2(b) and 2(c) show the beamcolumn element model and the detailed 3D finite element model, respectively.

The beam-column model is constructed in ANSYS, and an impact element is used to model the pounding effect. The stiffness $\left(k_{p}\right)$ and damping $\left(c_{p}\right)$ of the impact element are two important parameters that need to be determined. Previous investigation suggested a $k_{p}$ varying from 10 to 40 times of the lateral stiffness of the stiffer adjacent structures (Hao and Ma 1999). $k_{p}$ is assumed to be $5000 \mathrm{MN} / \mathrm{m}$ in the present study as suggested by Chouw and Hao (2008b). The dashpot constant $c_{p}$ determines the energy dissipated during impact. It is determined by relating it to the coefficient of restitution $(e)$ at pounding as follows (Jankowski et al. 1998):

$$
c_{p}=2 \zeta_{p} \sqrt{k_{p} \frac{m_{s} m_{l}}{m_{s}+m_{l}}}
$$

with

$$
\zeta_{p}=\frac{-\ln e}{\sqrt{\pi^{2}+(\ln e)^{2}}}
$$

In the present study, $e=0.46$ is used (Malhotra 1998), which corresponds to a damping ratio of $\zeta_{p}=0.24$.

The 3D finite element model is also constructed in ANSYS, but the calculations are carried out by using LSDYNA. Eight-node solid elements of size $0.1 \mathrm{~m}$ are used for both decks and piers in the model. The treatment of sliding and impact along contact surfaces is an important issue in the modelling. To realistically consider the poundings between entire surfaces of adjacent bridge decks, the contact type CONTACT AUTOMATIC SURFACE TO SURFACE in LS-DYNA is employed owing to its effectiveness and simplicity for explicit analysis. This contact algorithm is used to avoid penetration at the contact interfaces. The method resists the slave nodes penetration via the placement of imaginary normal interface springs between the shorting nodes and contact surface. Each slave nodes defined is checked at every stage of the computer simulation for penetration through the master surface. When penetration is detected, an internal force provided by the interface spring is applied between the slave node and contact point to oppose the penetration action. The magnitude of the internal force is directly proportional to both the spring stiffness of the master surface and the penetration distance of the slave node. Unlike the contact element method, the pounding location is not predefined, 
the surface to surface and eccentric poundings thus can be conveniently considered by using this method.

The bridge is excited in the longitudinal direction only by the first $6.3 \mathrm{~s}$ of the 1940 North-South El Centro earthquake ground motion scaled to a peak ground acceleration (PGA) of $0.5 \mathrm{~g}$. All materials are assumed as linear elastic in the simulations. Figure 3 shows the structural responses obtained from the different models. As shown in Figure 3(a), the relative displacements in the longitudinal direction between the adjacent bridge decks obtained by using the lumped mass model (Malhotra 1998) are generally smaller than those based on the beam-column model and detailed 3D finite element model. These results are actually expected, since the lumped mass model only considers the fundamental vibration mode of each uncoupled system, the contribution of higher vibration modes are not

(a)

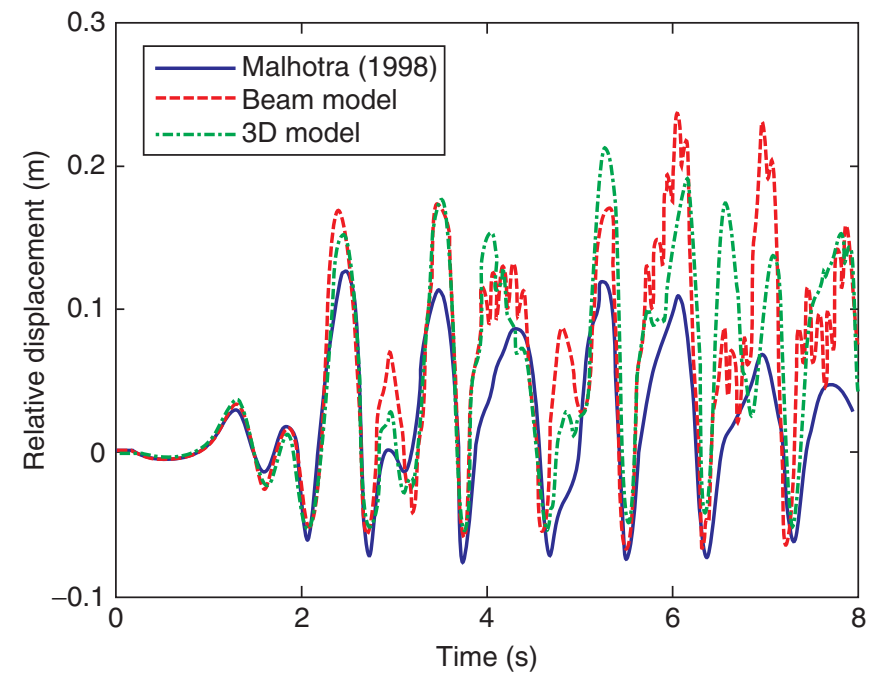

(b)

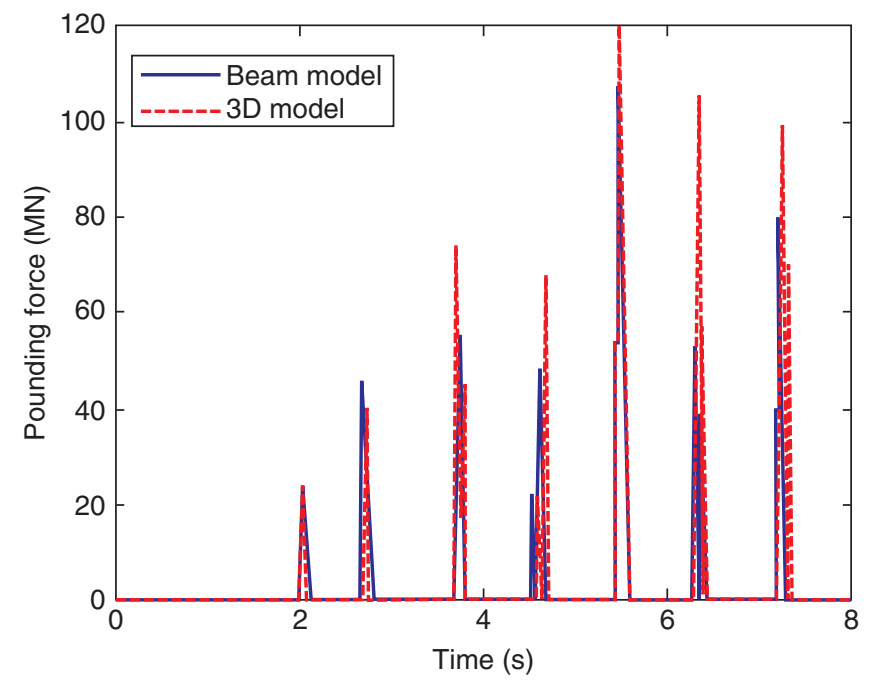

Figure 3. Structural responses based on different models: (a) relative displacement between bridge deck; and (b) pounding force involved. For the long-span bridge structure, the vibration frequencies for different vibration modes are close to each other, the contribution of higher vibration modes could be significant. Both the beam-column model and 3D model capture the influence of higher vibration modes. As a result, more high frequency oscillations can be observed in Figure 3(a). It also can be seen that the relative displacements based on these two models are very similar. The contact forces were not presented by Malhotra (1998) due to the limitation inherent in the method, but it was found that poundings occurred at 2.0, 2.7, 3.7, 4.6, 5.5, 6.3 and 7.3 s. Figure 3(b) shows the pounding forces based on the beamcolumn model and the 3D model. It can be seen that poundings occur at the time instants observed by Malhotra (1998). The pounding forces obtained from the 3D model are usually larger than those from the beam-column model. It should be noted that the pounding force obtained from the beam-column model depends on the pounding stiffness $k_{p}$ of the impact element, while the selection of $k_{p}$ is difficult since it depends on many factors and consequently the value can be varied in a wide range (Hao and Ma 1999). With a proper selection of $k_{p}$, closer results can be anticipated.

Based on the above analysis, it can be concluded that if earthquake ground excitation occurs only in the longitudinal direction of the bridge, all these three models can be used to calculate bridge pounding responses. However, the lumped mass model might underestimate the relative displacements between adjacent bridge decks. The beam-column model based on the contact element method can give reliable predictions of pounding responses if a proper pounding element with suitable stiffness and damping ratio is used. Therefore, if considering only uniaxial ground excitation in the longitudinal direction of the bridge, detailed 3D model is not necessary as it requires considerably more computational effort. In reality, however, earthquake ground motion is not limited to only one direction. Bridge structures inevitably subject to the excitations of multi-component and spatially varying ground motions. Spatially varying transverse ground motions induce coupled transverse and torsional responses of bridge decks even the bridge structures are symmetric. The torsional response might induce eccentric poundings between adjacent bridge decks as observed in Figure 1, and eccentric poundings in turn will cause more torsional responses. This 3D response characteristic cannot be captured with the lumped mass model or the 2D beam-column model. To realistically model 3D bridge responses involving possible surfaceto-surface and eccentric poundings, the use of a 3D finite element model is therefore necessary. 


\section{BRIDGE MODEL}

Figure 4(a) shows the elevation view of a two-span simply-supported bridge crossing a canyon site considered in this study. The box-section bridge girders with the cross section shown in Figure 4(b) have the same length of $50 \mathrm{~m}$. The Young's modulus and density of the girders are $3.45 \times 10^{10} \mathrm{~Pa}$ and $2500 \mathrm{~kg} / \mathrm{m}^{3}$, respectively. The L-type abutment is $8.1 \mathrm{~m}$ long in the transverse direction and its cross section is shown in Figure 4(c). The height of the rectangular central pier is $20 \mathrm{~m}$, with the cross section shown in Figure 4(d). The materials for the two abutments and the pier are the same, with Young's modulus and density of $3.0 \times 10^{10}$ $\mathrm{Pa}$ and $2400 \mathrm{~kg} / \mathrm{m}^{3}$, respectively. The two bridge girders are supported by 8 high-damping rubber bearings. The cross-sectional area and height of rubber layers in a single bearing are $0.7921 \mathrm{~m}^{2}$ and $0.082 \mathrm{~m}$. The horizontal effective stiffness and equivalent damping ratio of a bearing are $2.33 \times 10^{7} \mathrm{~N} / \mathrm{m}$ and 0.14 respectively (Jankowski et al. 1998; Zanardo et al.
2002). The stiffness of the bearing in the vertical direction is much larger than those in the horizontal directions, and is assumed to be $1.87 \times 10^{10} \mathrm{~N} / \mathrm{m}$ (Zanardo et al. 2002). To allow for contraction and expansion of the bridge decks from creep, shrinkage, temperature fluctuations and traffic without generating constraint forces in the structure, a $5 \mathrm{~cm}$ gap is introduced between the abutments and the bridge girders and between the adjacent bridge decks. It is noted that the lateral side stoppers, which are usually installed in practice, are not considered in the model. The bridge girders can vibrate freely in the transverse direction (z direction) when pounding is not involved.

The bridge is located on a canyon site, consisting of horizontally extended soil layers on a half-space (base rock). The foundations of the bridge are assumed rigidly fixed to the ground surface and SSI is not involved. Points $\mathrm{A}, \mathrm{B}$ and $\mathrm{C}$ are the three bridge support locations on the ground surface, the corresponding points on the base rock are A', B' and C'.

(a)

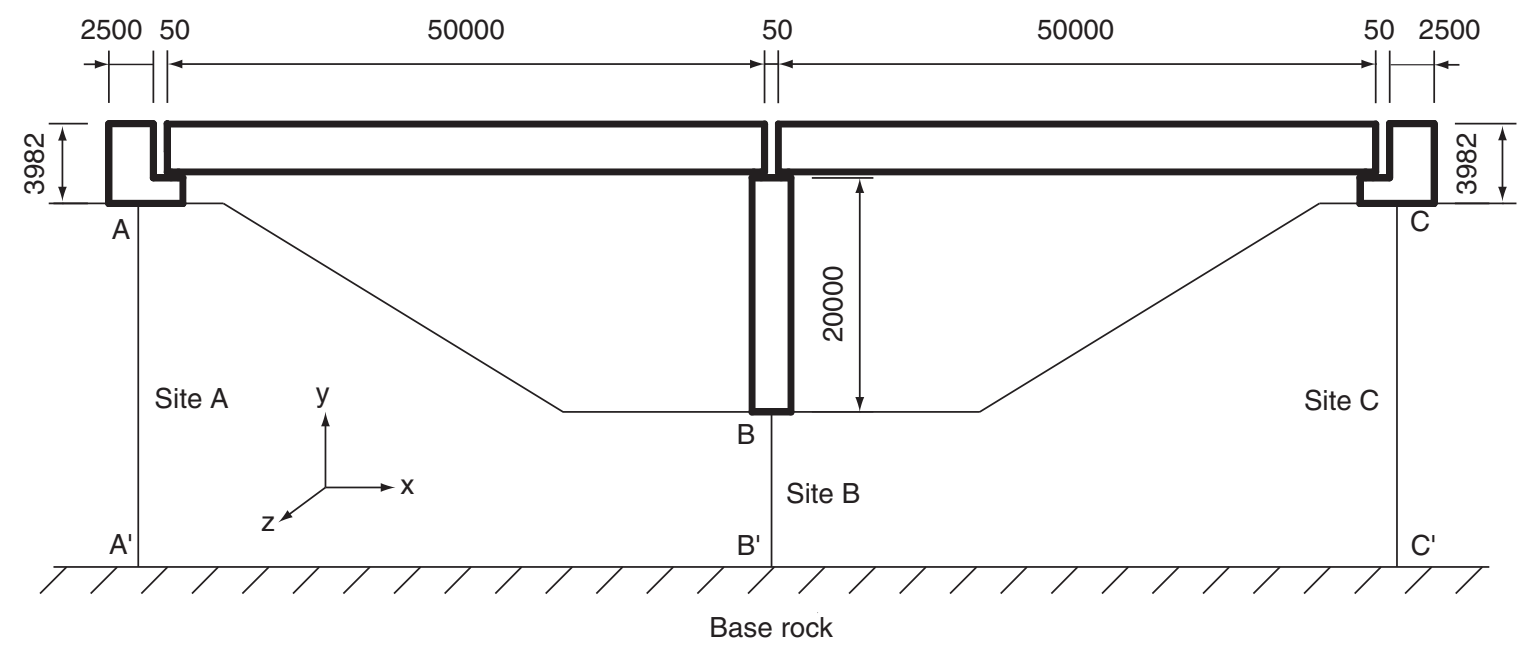

(b)

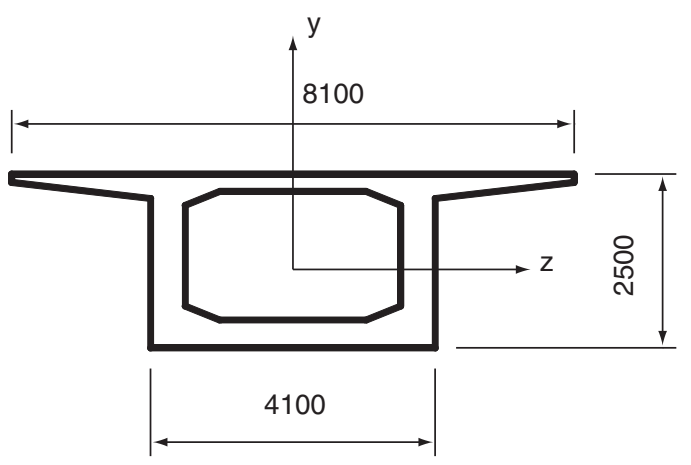

(c)

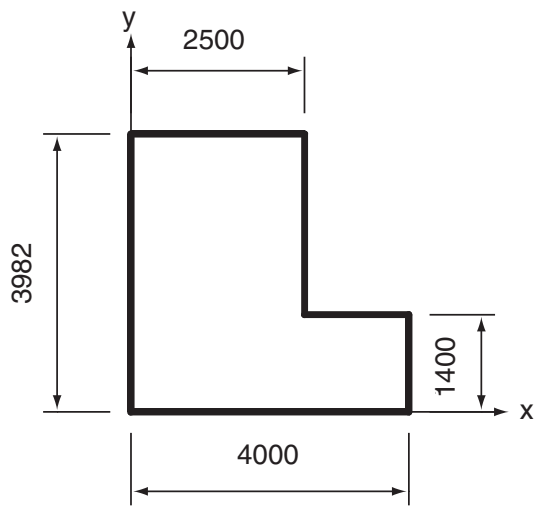

(d)

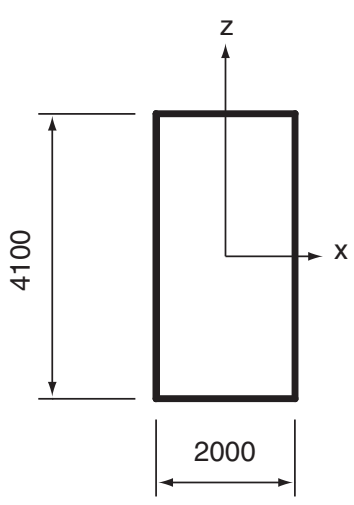

Figure 4. Bridge considered (a) elevation view; (b) cross-section of the bridge girder; (c) cross-section of the abutment; and (d) crosssection of the pier (unit: $\mathrm{mm}$ ) 
The 3D finite element model of the bridge is constructed by using the finite element code ANSYS (2009). The bridge girders, abutments and pier are modelled by eight-node solid elements. The bearings are modelled by the spring-dashpot elements. The detailed geometric characteristics in Figure 4 and the material properties are implemented in the model. To reduce the required computer memory and computational time, detailed modelling with fine mesh is only applied to the areas near the contact surfaces. In particular, detailed modelling with the mesh size of 0.2 $\mathrm{m}$ is only applied to a length of $1 \mathrm{~m}$ from each end of the bridge deck and to a length of $0.6 \mathrm{~m}$ of the abutments. Beyond this region, the mesh size in the longitudinal direction is $1 \mathrm{~m}$. Figure 5 shows fine meshed areas of the model (the numbers in the circles are the nodes examined in the present study, which will be discussed in Section 5). For a convergence test, a smaller mesh size of $0.1 \mathrm{~m}$ around the contact areas is also conducted. Numerical results show that the structural responses are almost the same for the two different mesh sizes. It should be noted that, only the linear elastic responses are considered in the present study, smaller mesh size might be needed if local damages are involved. Figure 6 shows the first four vibration frequencies and the corresponding vibration modes of the bridge. As shown, the first four vibration frequencies of the bridge equal to $1.081,1.138,1.254$ and $1.313 \mathrm{~Hz}$ for the in-phase longitudinal (x direction), in-phase transverse ( $\mathrm{z}$ direction), out-of-phase transverse and out-of-phase longitudinal vibrations, respectively.

Rayleigh damping is assumed in the model to simulate energy dissipation during structural vibrations. The first two vibration modes are chosen to determine the mass and stiffness coefficients, because the horizontal displacement in the longitudinal and transverse directions is of special interest due to its
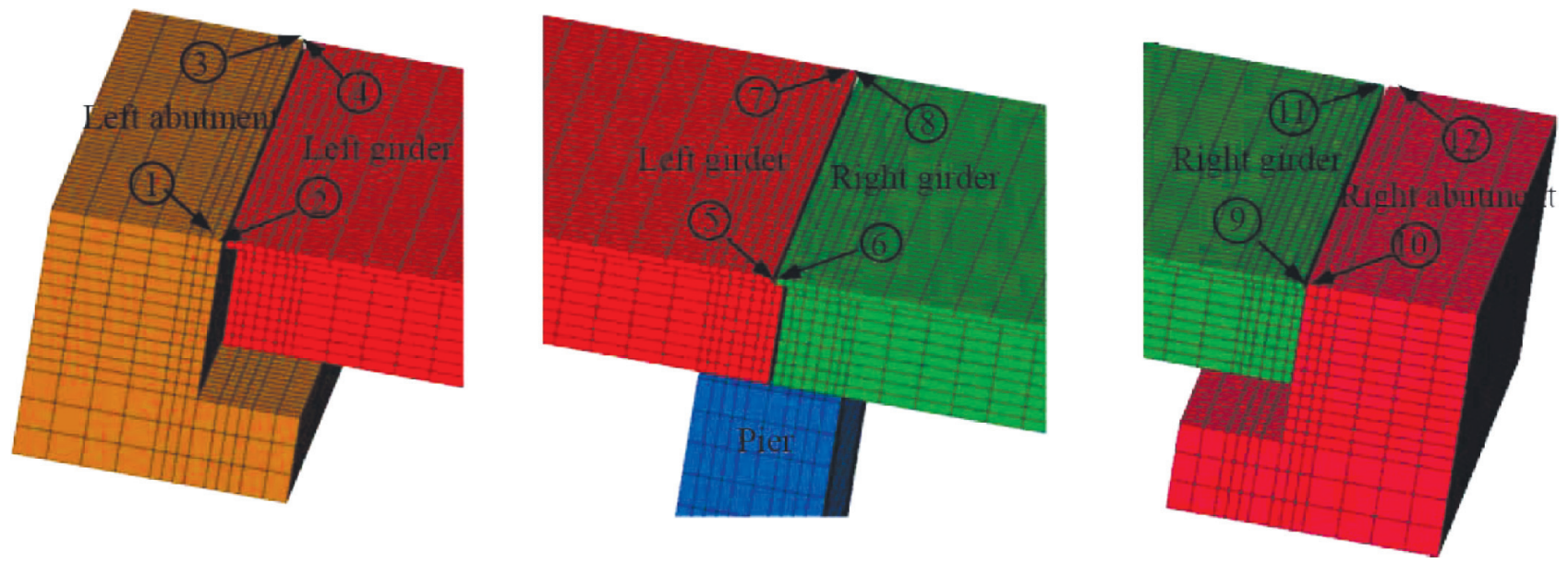

Figure 5. Finite element mesh of the bridge and the nodal points for response recordings

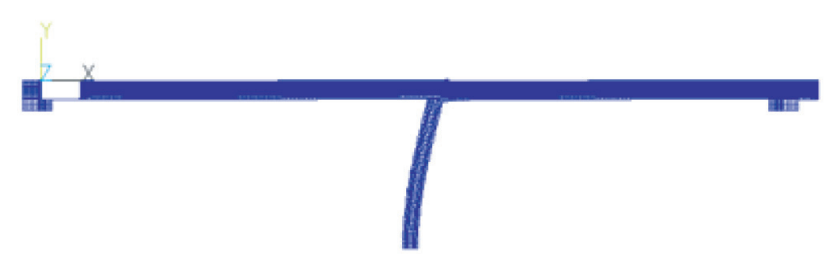

(a) $f_{1}=1.081 \mathrm{~Hz}$

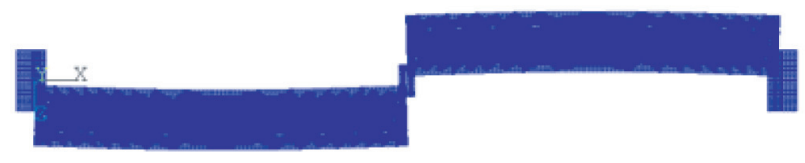

(c) $f_{3}=1.254 \mathrm{~Hz}$

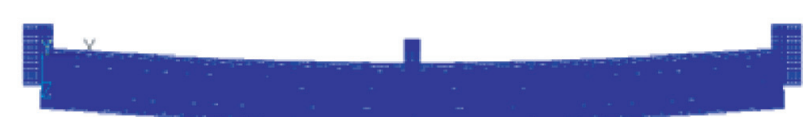

(b) $f_{2}=1.138 \mathrm{~Hz}$

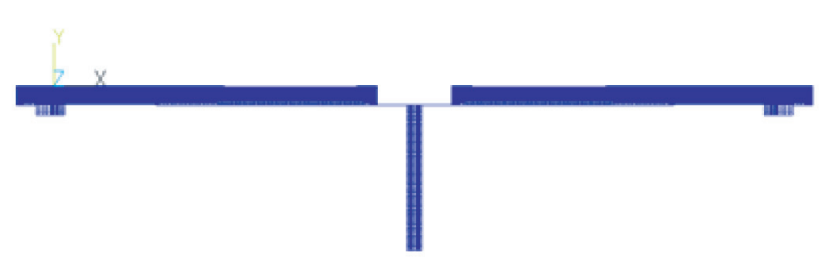

(d) $f_{4}=1.313 \mathrm{~Hz}$

Figure 6. First four vibration frequencies and mode shapes of the bridge 
significant importance in the pounding responses. By assuming the structural damping ratio of $5 \%$, for these two modes, the mass matrix multiplier is obtained as 0.3483 and the stiffness matrix multiplier is 0.0072 . The contact algorithm of CONTACT AUTOMATIC SURFACE TO SURFACE in LS-DYNA is employed to model impact between the adjacent structures. The Coulomb friction coefficient of 0.5 is assumed in the analysis (Jankowski 2009).

\section{SPATIALLY VARYING GROUND MOTIONS}

For the canyon site as shown in Figure 4, local site will significantly change the amplitudes and frequency contents of the incoming waves on the base rock owing to the amplification and filtering effect. The three sites (A, B and C) have different influences on base rock motions, thus further intensifies the spatial variations of the ground motions. However, traditional method (e.g. Hao et al. 1989) for simulating the spatially varying ground motions is based on the assumption of a flat site and the influence of local soil conditions is not considered. With such an assumption, ground motions at the three sites on ground surface have the same intensity and frequency contents. More recently, Bi and Hao (2012) developed an approach to stochastically simulate the spatially varying motions on the ground surface of a canyon site. In the method, the base rock motions are assumed to consist of out-of-plane SH wave and in-plane combined $\mathrm{P}$ and $\mathrm{SV}$ waves propagating into the site with an assumed incident angle. The power spectral density function on the base rock is assumed to be the same, and is modelled by a filtered Tajimi-Kanai power spectral density function (Tajimi 1960). The spatial variation of ground motions at base rock is modelled by an empirical coherency function. Local site effect is modelled using the one-dimensional wave propagation theory (Wolf 1985). The power spectral density functions of the horizontal in-plane, horizontal out-of-plane and vertical in-plane motions on the ground surface can thus be formulated by considering local site effect in the corresponding directions. The multi-component spatially varying ground motions can then be simulated by using the approach similar to the traditional method. This approach directly relates site amplification effect with local soil conditions, and can capture the multiple vibration modes of local site, is believed more realistically simulating the multicomponent spatially varying motions on surface of a canyon site.

The ground motion intensities at points A', B' and C' on the base rock are assumed to be the same and have the following form:

$$
\begin{aligned}
& S_{g}(\omega)= \\
& \frac{\omega^{4}}{\left(\omega_{f}^{2}-\omega^{2}\right)^{2}+\left(2 \omega_{f} \omega \xi_{f}\right)^{2}} \frac{1+4 \xi_{g}^{2} \omega_{g}^{2} \omega^{2}}{\left(\omega_{g}^{2}-\omega^{2}\right)^{2}+4 \xi_{g}^{2} \omega_{g}^{2} \omega^{2}} \Gamma
\end{aligned}
$$

where $\omega_{g}$ and $\xi_{g}$ are the central frequency and damping ratio of the Tajimi-Kanai power spectral density function, $\omega_{f}$ and $\xi_{f}$ are the corresponding central frequency and damping ratio of the high pass filter function. $\Gamma$ is a scaling factor depending on the ground motion intensity. In the analysis, the out-of-plane horizontal motion is assumed to consist of SH wave only, while the in-plane horizontal and vertical motions are assumed to be combined $\mathrm{P}$ and $\mathrm{SV}$ waves. The parameters for the horizontal motion are assumed as $\omega_{g}=10 \pi \mathrm{rad} / \mathrm{s}, \xi_{g}=0.6, \omega_{f}=0.5 \pi, \xi_{f}=0.6$ and $\Gamma=0.0232 \mathrm{~m}^{2} / \mathrm{s}^{3}$. These parameters correspond to a ground motion time history with duration $T=16 \mathrm{~s}$ and PGA of $0.5 \mathrm{~g}$ based on the standard random vibration method (Der Kiureghian 1980). The vertical motion on the base rock is also modelled with the same filtered TajimiKanai power spectral density function, but the amplitude is assumed to be $2 / 3$ of the horizontal component.

The Sobczyk model (Sobczyk 1991) is selected to describe the coherency loss between the ground motions at points $j^{\prime}$ and $k^{\prime}$ (where $j^{\prime}, k^{\prime}$ represents $\mathrm{A}^{\prime}, \mathrm{B}^{\prime}$ or $\mathrm{C}^{\prime}$ ) on the base rock:

$$
\begin{aligned}
\gamma_{j k^{\prime}}(i \omega)= & \left|\gamma_{j k^{\prime}}(i \omega)\right| \exp \left(-i \omega d_{j k^{\prime}} \cos \alpha / v_{a p p}\right) \\
= & \exp \left(-\beta \omega d_{j^{\prime}}^{2} / v_{a p p}\right) \\
& \times \exp \left(-i \omega d_{j^{\prime} k^{\prime}} \cos \alpha / v_{a p p}\right)
\end{aligned}
$$

where $\beta$ is a coefficient reflecting the level of coherency loss. $\beta=0.0,0.001$ and 0.002 are considered in the present paper, which represent perfectly correlated spatial ground motions, or spatial ground motion with wave passage effect only, intermediately and weakly correlated motions, respectively. $d_{j^{\prime} k^{\prime}}$ is the distance between the points $j^{\prime}$ and $k^{\prime}$. For the analysed bridge structure, $d_{A^{\prime} B^{\prime}}=$ $d_{B^{\prime} C^{\prime}}=50 \mathrm{~m}$, and $d_{A^{\prime} C^{\prime}}=100 \mathrm{~m}$. $v_{\text {app }}$ is the apparent wave velocity on the base rock, which is related to the base rock property and incident angle $\alpha$. With the given properties of local site (shown in Table 1) and assumed incident angle $\alpha=60^{\circ}, v_{a p p}$ equals $1697 \mathrm{~m} / \mathrm{s}$ in the present study.

Table 1. Parameters for local site conditions.

\begin{tabular}{lcccc}
\hline Type & $\begin{array}{c}\text { Shear } \\
\text { Density } \\
\left(\mathbf{k g} / \mathbf{m}^{\mathbf{3}}\right)\end{array}$ & $\begin{array}{c}\text { modulus } \\
\text { (MPa) }\end{array}$ & $\begin{array}{c}\text { Damping } \\
\text { ratio }\end{array}$ & $\begin{array}{c}\text { Poisson's } \\
\text { ratio }\end{array}$ \\
\hline Base rock & 2500 & 1800 & 0.05 & 0.33 \\
Firm soil & 2000 & 320 & 0.05 & 0.4 \\
Soft soil & 1600 & 40 & 0.05 & 0.4 \\
\hline
\end{tabular}


Not to further complicate the problem, only one single layer resting on the base rock is considered, and the soil properties at sites A, B and C are assumed to be the same, the only difference is the soil depth. In the present study, the depths for the three local sites are 48.6, 30 and $48.6 \mathrm{~m}$ respectively. To study the influence of local soil conditions, two types of soil, i.e. firm and soft soils, are considered. Table 1 gives the corresponding parameters for the soils and base rock. It should be noted that to limit the considered influence factors, SSI is not considered even when the bridge model locates on a soft soil site.

With the proposed approach (Bi and Hao 2012) and the given parameters of local site, the horizontal in-plane, horizontal out-of-plane and vertical in-plane motions on the ground surface can be simulated. It should be noted that a series of random phase angles uniformly distributed over the range of $[0,2 \pi]$ are included in the simulation. For each realization of the phase angles, one set of ground motion time histories can be simulated. Since most design codes require 2 to 4 independent analyses with independently simulated ground motions as input and take the averaged structural responses, in this study, three sets of multi-component spatially varying ground motions are independently simulated and used as input in the analysis.
In the simulation, the sampling frequency and the upper cut-off frequency are set to be 100 and $25 \mathrm{~Hz}$ respectively, and the time duration is assumed to be $T=16 \mathrm{~s}$. Figures 7 and 8 show the simulated three-dimensional spatially varying acceleration and displacement time histories on ground surface corresponding to the soft soil conditions with intermediate coherency loss. Figure 9 shows the comparisons of the simulated power spectral densities with the theoretical values of the horizontal in-plane motions, good agreements are observed. For conciseness, the comparisons of the horizontal out-of-plane and vertical in-plane motions are not plotted. Good agreements for these two ground motion components are also observed. For the coherency loss function between the motions on the ground surface, Bi and Hao (2011) indicated that it is different from that on the base rock. The spatial ground motions on ground surface are least correlated when the spectral ratios of two local sites differ from each other significantly. Discussion of the influence of local soil condition on spatial ground motion coherency loss is out of the scope of the present study. More detailed information can be found in $\mathrm{Bi}$ and Hao (2011). It should be noted that the simulated spatial ground motions corresponding to the firm soil condition also match the model values very well.

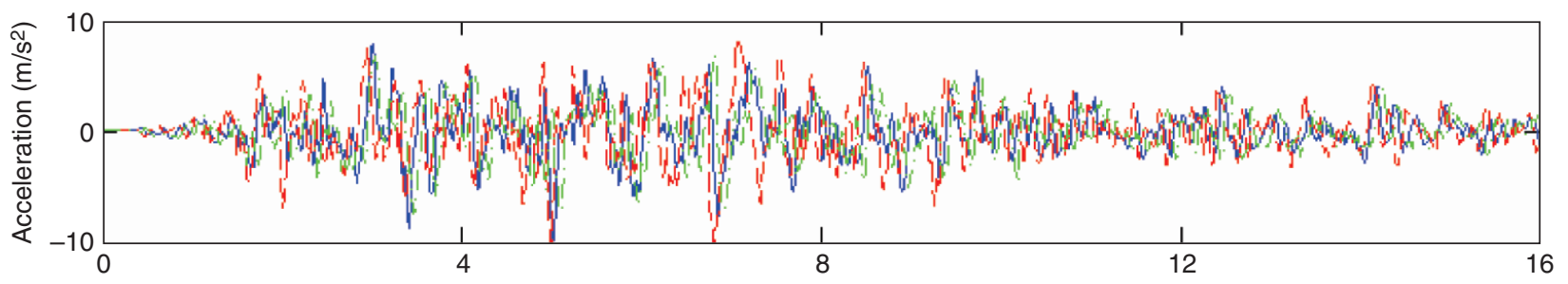

(a) Horizontal in-plane motion

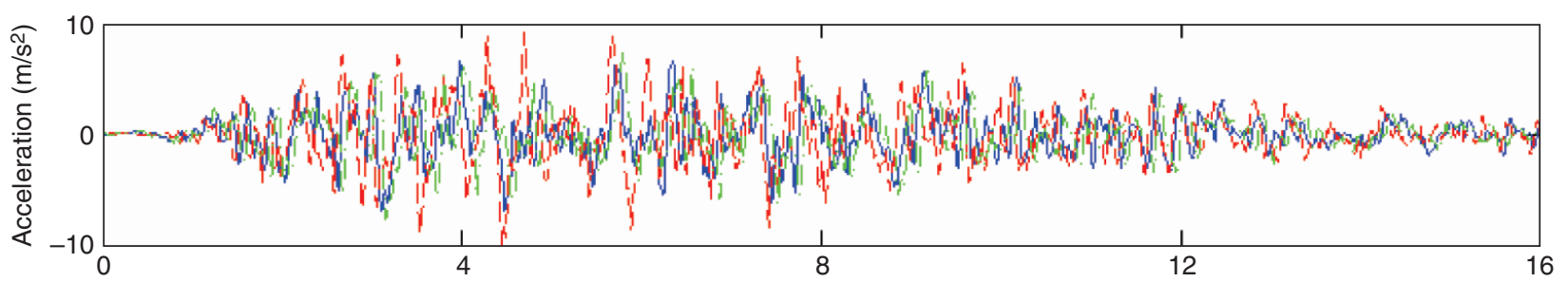

(b) Horizontal out-of-plane motion

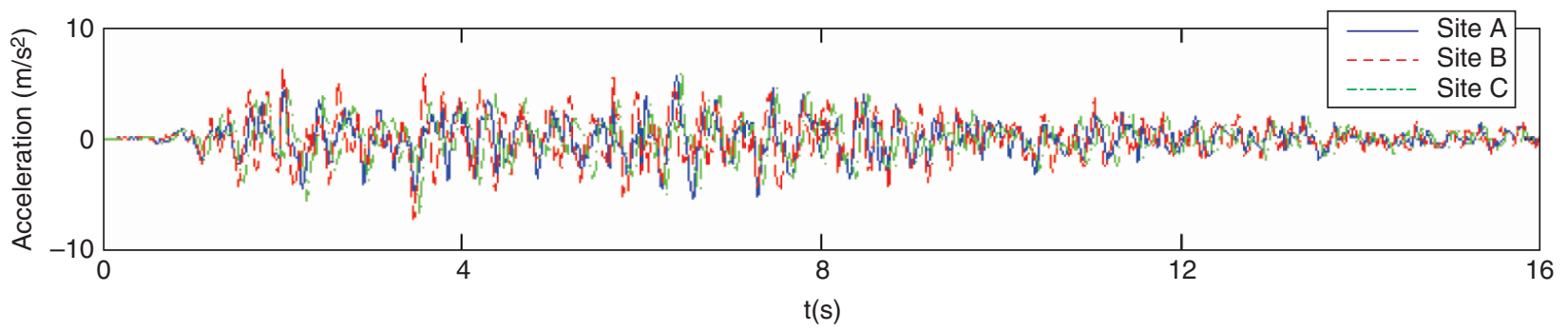

(c) Vertical in-plane motion

Figure 7. Simulated acceleration time histories with soft soil condition and intermediately correlated coherency loss 


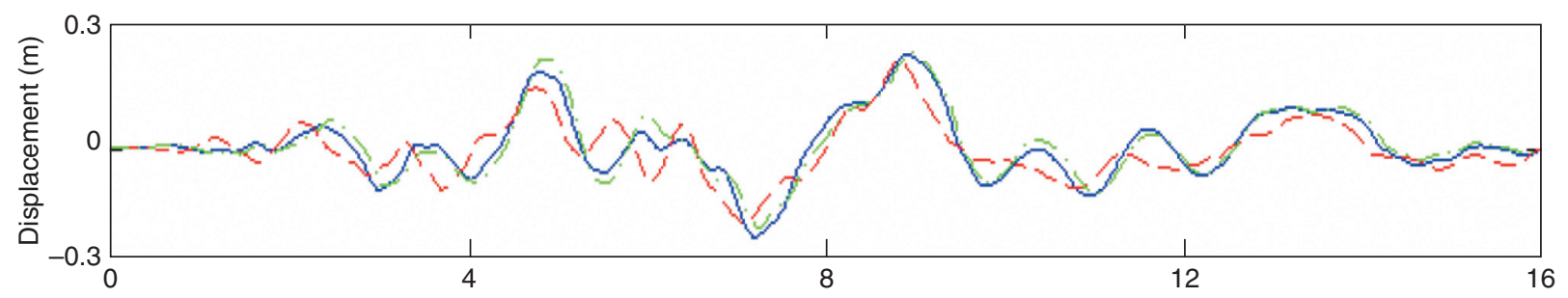

(a) Horizontal in-plane motion

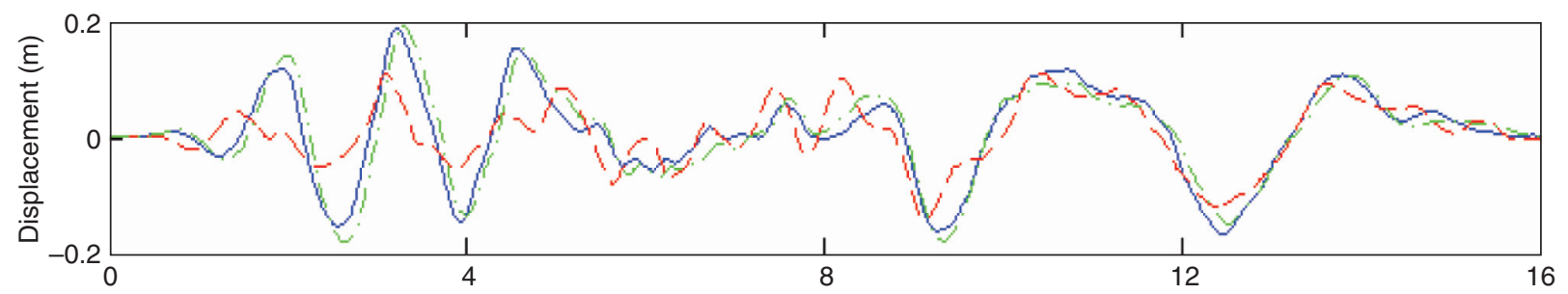

(b) Horizontal out-of-plane motion

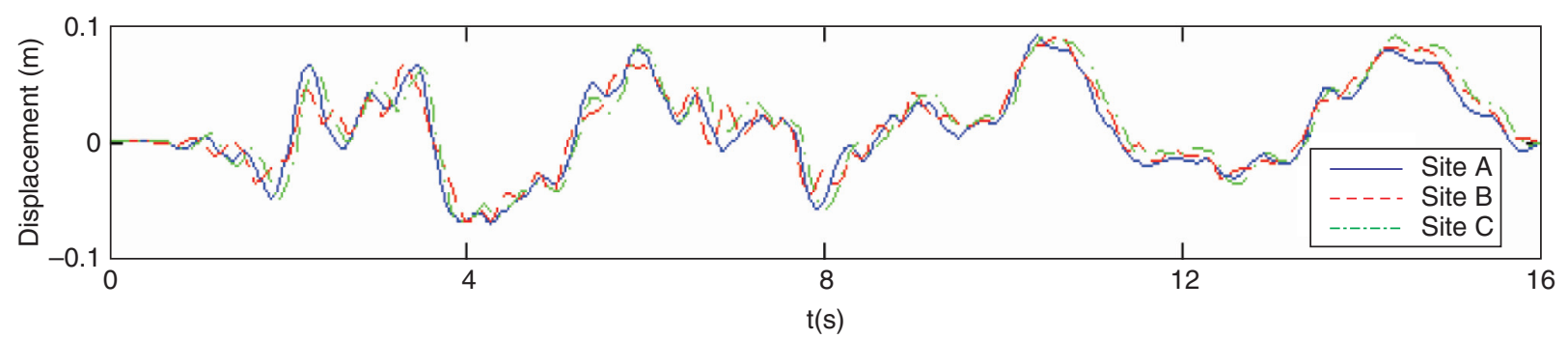

(c) Vertical in-plane motion

Figure 8. Simulated displacement time histories with soft soil condition and intermediately correlated coherency loss

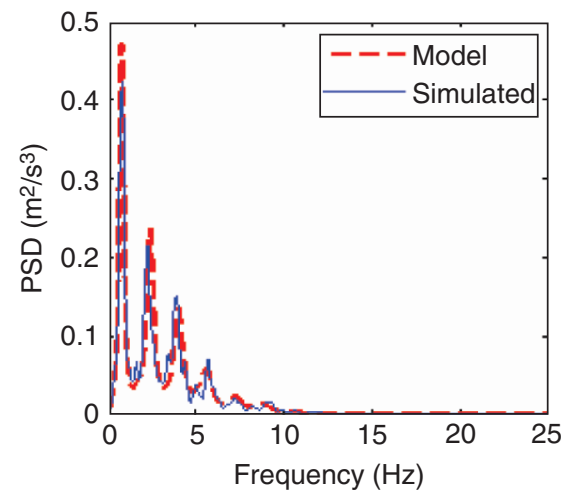

(a) Site $\mathrm{A}$

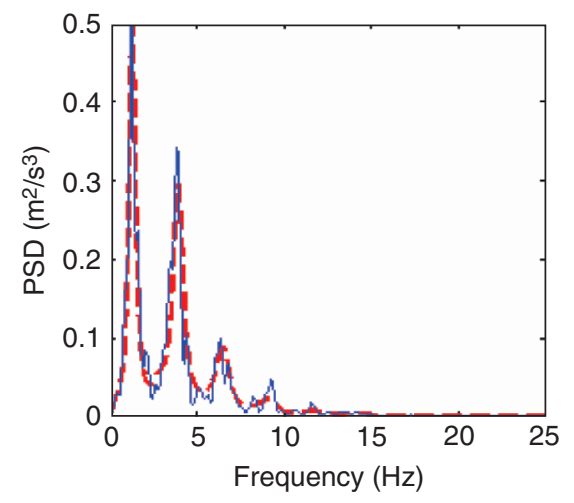

(b) Site B

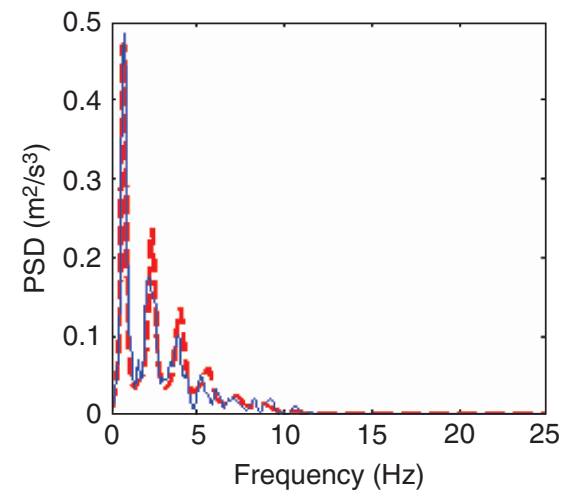

(c) Site C

Figure 9. Comparison of PSDs between the generated horizontal in-plane soft soil motions on ground surface with the respective theoretical model values

\section{NUMERICAL RESULTS}

Based on the discussion above, the computational steps of the pounding responses of bridge structures to spatially varying ground motions are briefly summarized as follows: (1) develop the numerical model in LS-DYNA and apply the contact algorithm (CONTACT AUTOMATIC SURFACE TO SURFACE) in the pounding prone area; (2) simulate the multicomponent spatially varying ground motions at different supports of the bridge based on the properties of local soils and base rock; (3) apply the simulated horizontal in-plane, horizontal out-of-plane and vertical in-plane displacement time histories simultaneously along the longitudinal, transverse and vertical directions of the bridge; (4) carry out the structural response calculation in LS-DYNA.

Follow the four computational steps, the earthquakeinduced pounding responses of the two-span 
Table 2. Different cases studied

\begin{tabular}{lccc}
\hline Case & $\begin{array}{c}\text { Soil } \\
\text { conditions }\end{array}$ & $\begin{array}{c}\text { Coherency } \\
\text { loss }\end{array}$ & $\begin{array}{c}\text { With/without } \\
\text { pounding }\end{array}$ \\
\hline 1 & Firm & intermediately & without \\
2 & Firm & intermediately & with \\
3 & Soft & intermediately & with \\
4 & Firm & wave passage effect & with \\
5 & Firm & weakly & with \\
\hline
\end{tabular}

simply-supported bridge shown in Figure 4 are discussed in detail in this section. To investigate the influence of pounding, local soil conditions and ground motion spatial variations on the structural responses, five different cases as shown in Table 2 are considered. In which, the case without pounding (Case 1) is simulated by adjusting the model to make the separation gaps between the abutment and the girder and between two adjacent girders large enough so that pounding phenomenon can be completely precluded and the structure vibrates freely.

In the cases 2-5, poundings may occur between the abutments and the adjacent bridge girders and between two adjacent bridge girders as mentioned above. Although the bridge considered is a symmetrical structure, the response of different parts will be different owing to the ground motion spatial variation and pounding effect. To obtain a general idea of the earthquake-induced structural responses, the 12 nodes as indicated in Figure 5 are selected to record the results.
Three simulations using the three sets of independently simulated spatially varying ground motions as inputs for each case are carried out, and the mean peak responses, which are mostly concerned in engineering practice, are calculated and discussed. For a better understanding of the results, the time histories of the structural response corresponding to a particular set of ground motions are also displayed when necessary.

\subsection{Longitudinal Response}

Figures 10-12 show the longitudinal displacement response time histories at nodes 1 and 2 of different ground motion cases. For conciseness, the response time histories of other nodes are not plotted. The mean peak displacements of different nodes are listed in Table 3. As shown in Figure 10(a), the longitudinal displacement response of node 1 is almost unaffected by the poundings owing to the fact that the abutment is quite rigid as compared to the adjacent girder. Similar observations were obtained by Maragakis et al. (1991), who investigated the influences of abutment and deck stiffness, gap, and deck to abutment mass ratio on the pounding responses between abutments and bridge decks, and concluded that pounding effect on rigid abutment is not evident. The influence of collisions on the girder response is, however, significant. As shown in Figure 10(b), the peak displacements of node 2 in the longitudinal direction with and without pounding effect are 0.210 and $0.274 \mathrm{~m}$ respectively, poundings result in a reduction of displacement response by $23.4 \%$. This is

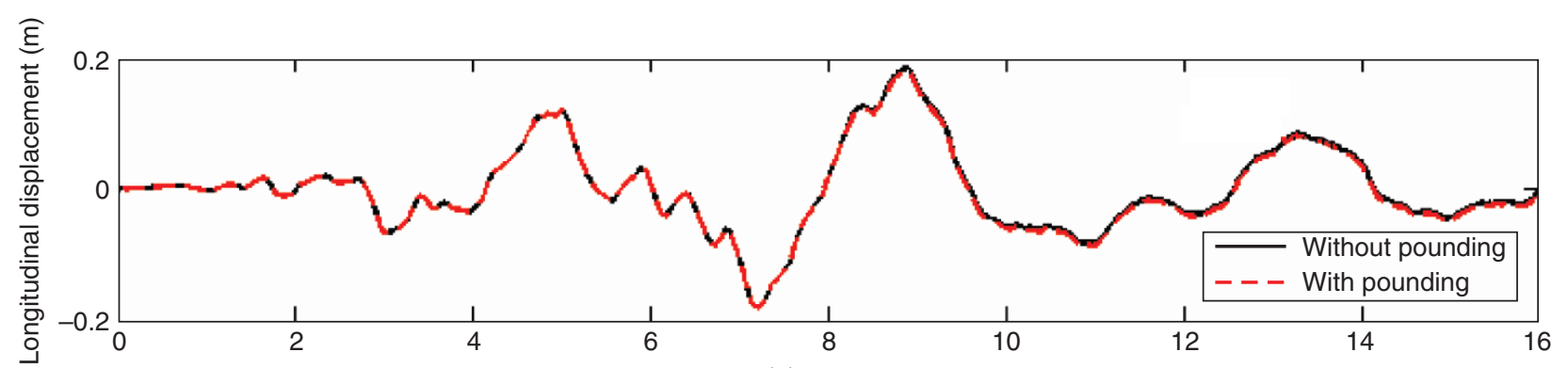

(a) Node 1

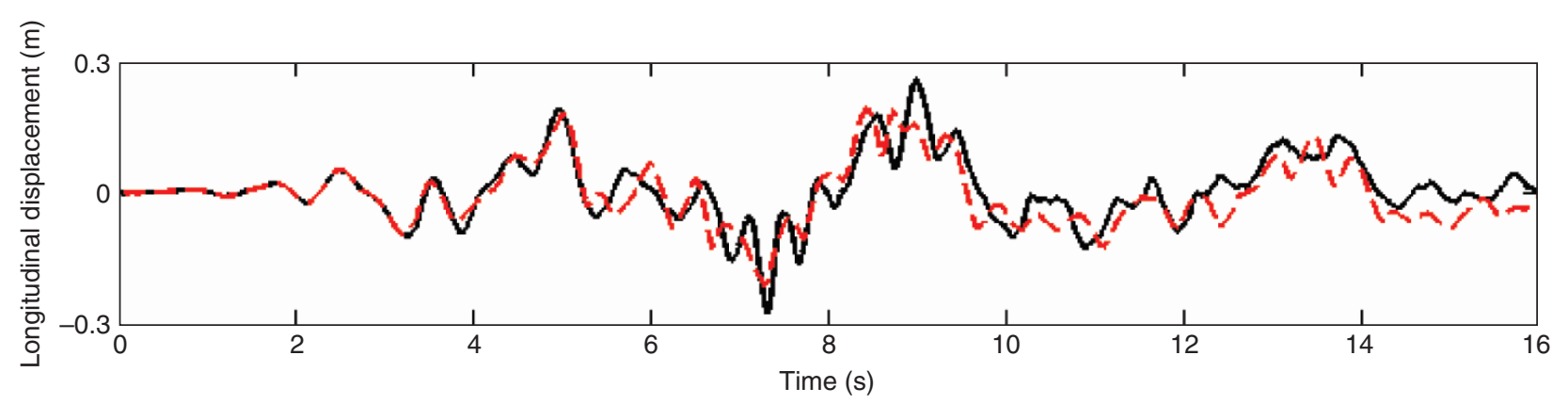

(b) Node 2

Figure 10. Influence of pounding on the longitudinal displacement response 


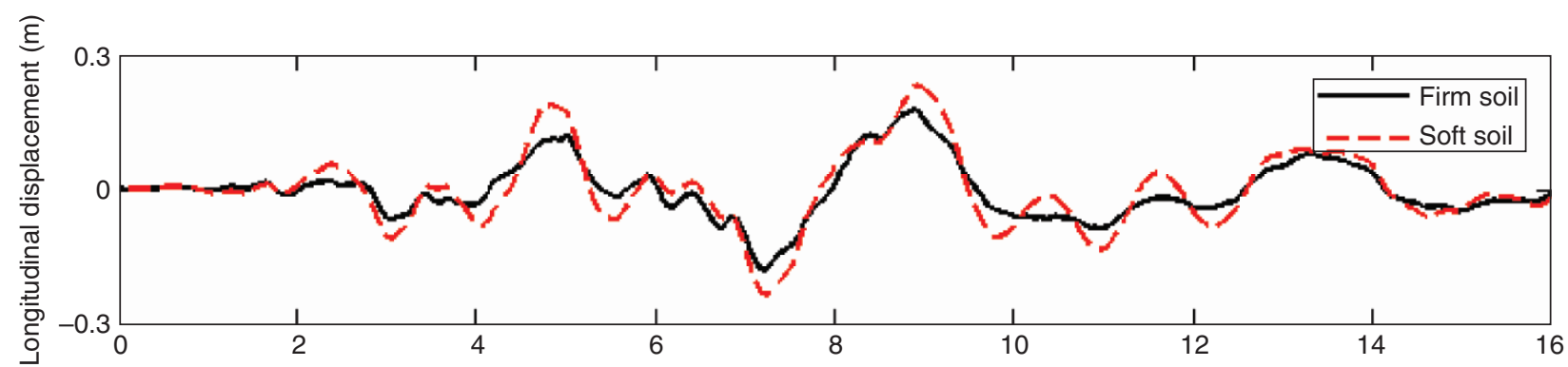

(a) Node 1

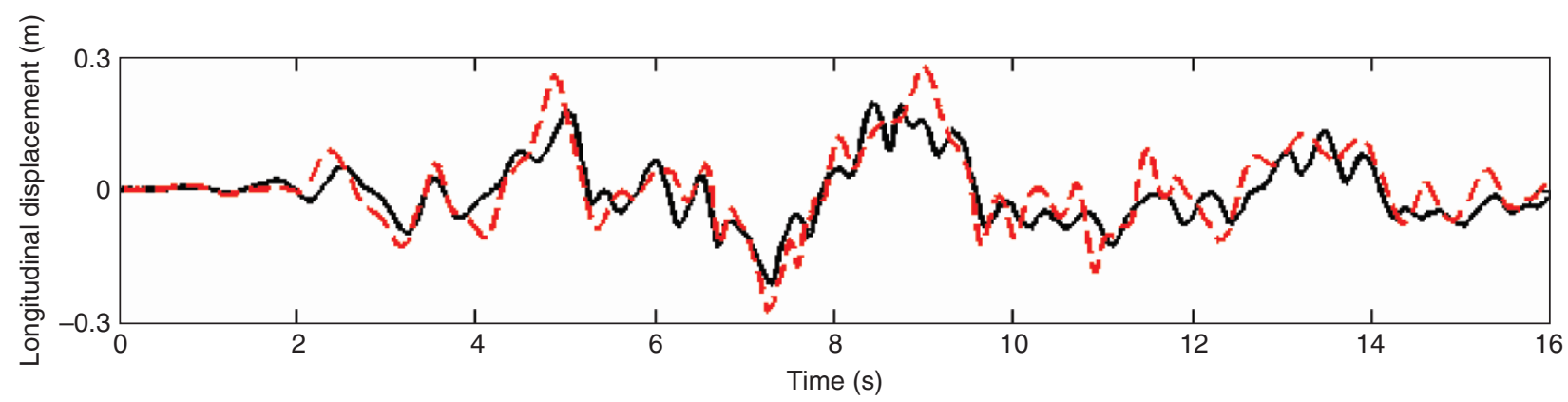

(b) Node 2

Figure 11. Influence of soil conditions on the longitudinal displacement response

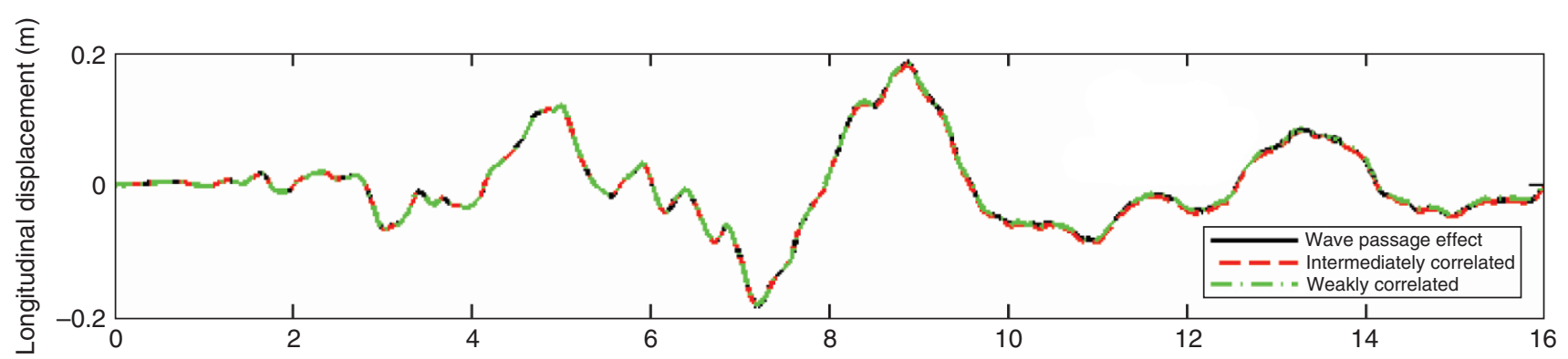

(a) Node 1

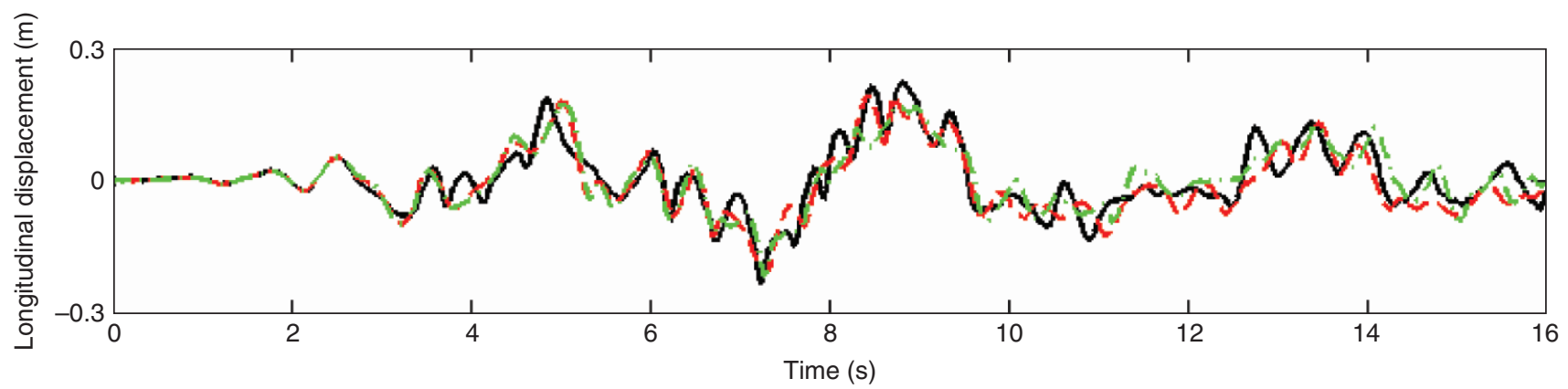

(b) Node 2

Figure 12. Influence of coherency loss on the longitudinal displacement response

because the rigid abutment acts as a constraint to the flexible girder. Comparing the mean peak responses of different nodes of Cases 1 and 2 in Table 3, same conclusions can be obtained.

The influence of local soil conditions on the structural response is shown in Figure 11. As shown, softer soil results in lager longitudinal displacement.
Taking node 2 for example, the peak displacements are 0.210 and $0.276 \mathrm{~m}$ for firm and soft soil, respectively. This is because softer soil usually leads to larger ground displacements at the foundations of the structure, which results in larger total structural displacement responses. Comparing the mean peak responses of cases 2 and 3 in Table 3, same conclusions can be drawn. 
Table 3. Mean peak displacements in the longitudinal direction (m)

\begin{tabular}{lccccc}
\hline & \multicolumn{5}{c}{ Case } \\
\cline { 2 - 6 } Node & $\mathbf{1}$ & $\mathbf{2}$ & $\mathbf{3}$ & $\mathbf{4}$ & $\mathbf{5}$ \\
\hline 1 & 0.147 & 0.148 & 0.204 & 0.149 & 0.151 \\
2 & 0.216 & 0.168 & 0.220 & 0.177 & 0.163 \\
3 & 0.147 & 0.148 & 0.203 & 0.148 & 0.147 \\
4 & 0.227 & 0.176 & 0.233 & 0.190 & 0.173 \\
5 & 0.200 & 0.167 & 0.235 & 0.182 & 0.161 \\
6 & 0.203 & 0.169 & 0.234 & 0.183 & 0.157 \\
7 & 0.215 & 0.173 & 0.233 & 0.191 & 0.158 \\
8 & 0.226 & 0.176 & 0.244 & 0.177 & 0.165 \\
9 & 0.206 & 0.168 & 0.231 & 0.177 & 0.151 \\
10 & 0.140 & 0.140 & 0.191 & 0.146 & 0.138 \\
11 & 0.205 & 0.170 & 0.223 & 0.169 & 0.168 \\
12 & 0.140 & 0.139 & 0.191 & 0.146 & 0.138 \\
\hline
\end{tabular}

The influence of coherency loss on the longitudinal displacement is shown in Figure 12. As shown in Figure 12(a), the influence of coherency loss on node 1 displacement is insignificant. This is because the ground motions propagate from left to right in the present study, the simulated ground motion time histories at site $\mathrm{A}$ are the same for the three sets of ground motions of each considered cases. The influence is expected for nodes at the girders and right abutment. As shown in Figure 12(b), different coherency loss results in different longitudinal displacements of node 2 . By examining the mean peak responses of cases 2,4 , and 5 in Table 3, it is generally true that the higher is the correlation between spatial ground motions, the larger is the longitudinal mean peak responses.

\subsection{Transverse and Vertical Responses}

As will be demonstrated, the influences of different site and ground motion parameters on the transverse and vertical displacement responses of the bridge follow the same pattern, so they are discussed together in this section. Figures 13-15 show the response time histories in the transverse direction of nodes 1 and 2 , and the corresponding time histories in the vertical direction are plotted in Figures 16-18. The mean peak responses in the transverse and vertical directions are listed in Tables 4 and 5, respectively. Similar to the responses in the longitudinal direction, the influence of poundings on displacement response of the abutments can be neglected. However, the influence on responses of the bridge girder is evident. Poundings usually result in smaller peak transverse and vertical displacements. This is because of the friction forces between the adjacent surfaces during poundings, which reduce the responses of the bridge structures in the transverse and vertical directions. As shown in Figures 14 and 17 and Tables 4 and 5 for the responses in the transverse and vertical directions, softer soil condition always results in larger displacement responses as discussed previously. Ground motion spatial variations affect bridge responses, especially the responses of bridge decks. As shown in Tables 4 and 5, weakly correlated ground motions, among the three spatial ground motion cases, usually lead to the largest

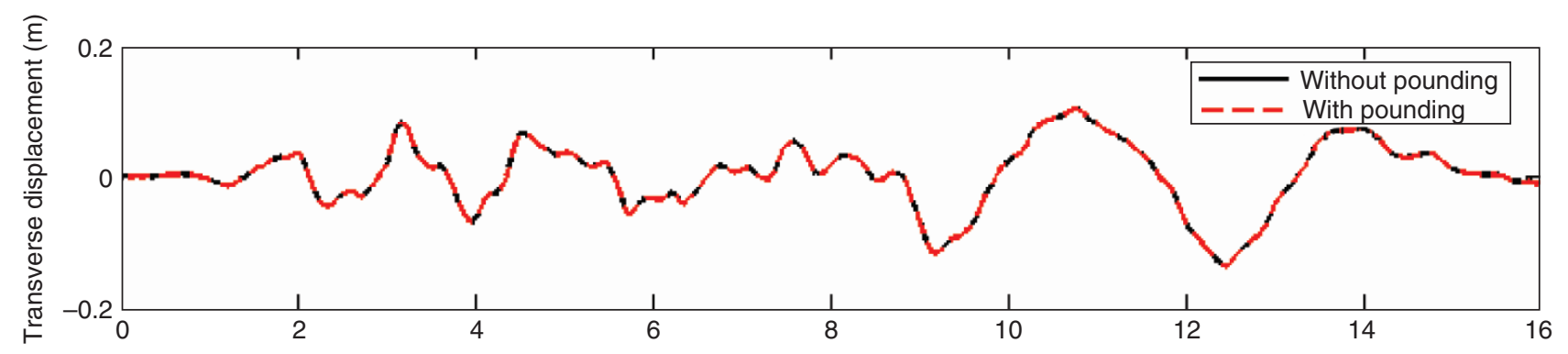

(a) Node 1

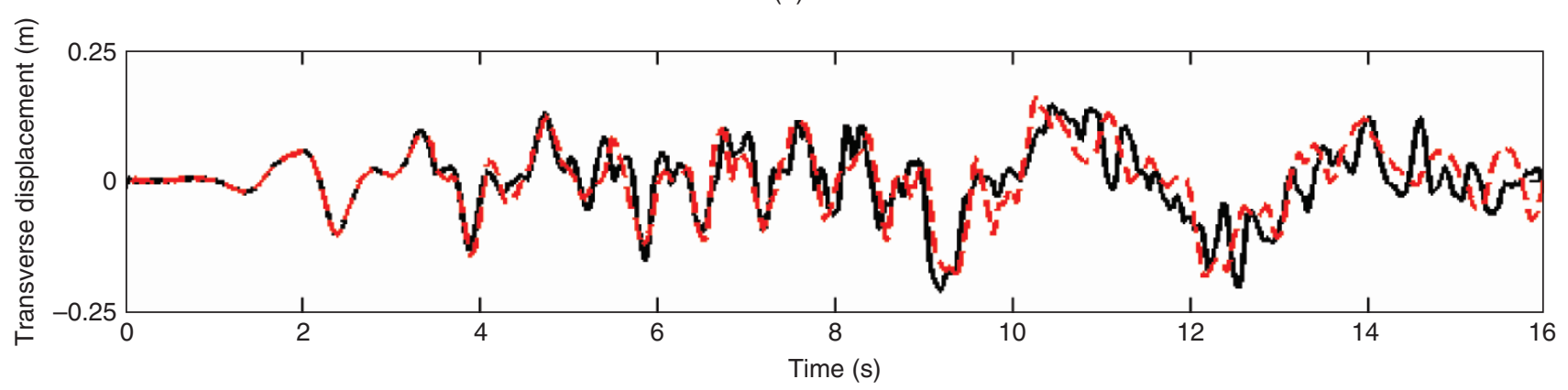

(b) Node 2

Figure 13. Influence of pounding on the transverse displacement response 


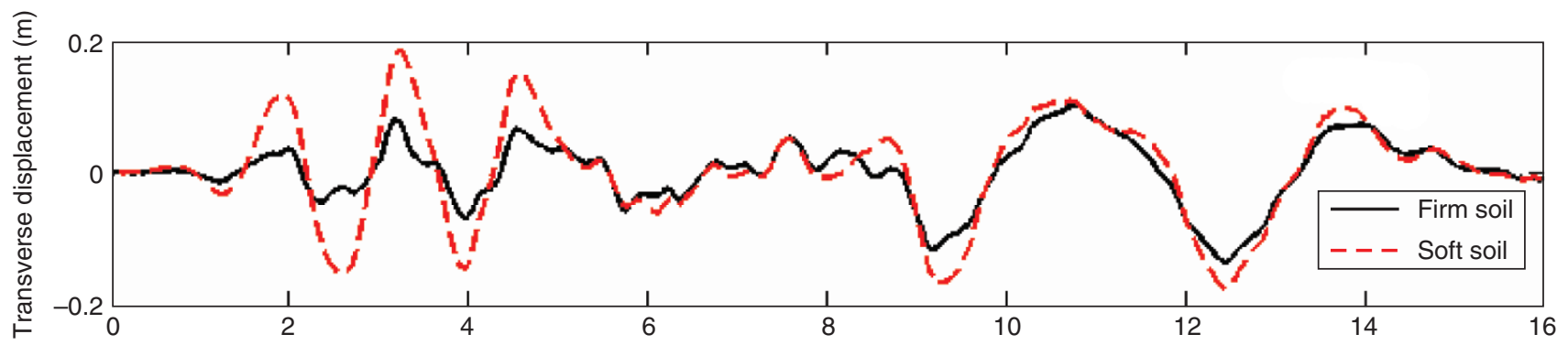

(a) Node 1

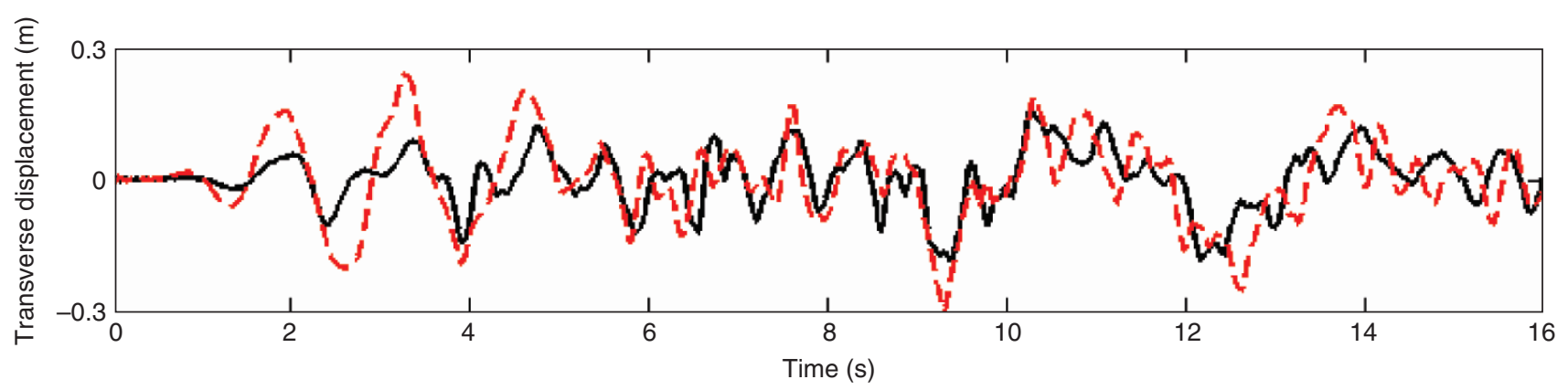

(b) Node 2

Figure 14. Influence of soil conditions on the transverse displacement response

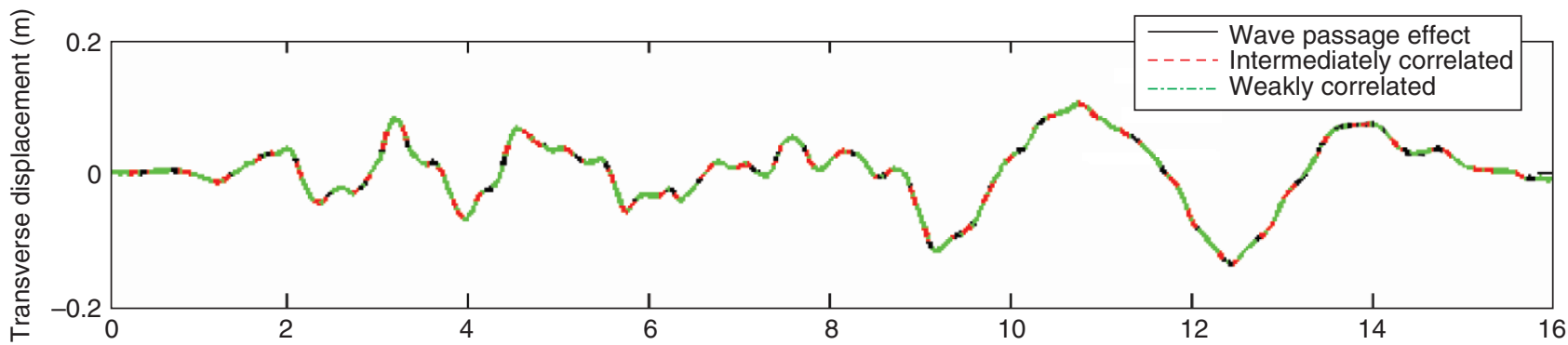

(a) Node 1

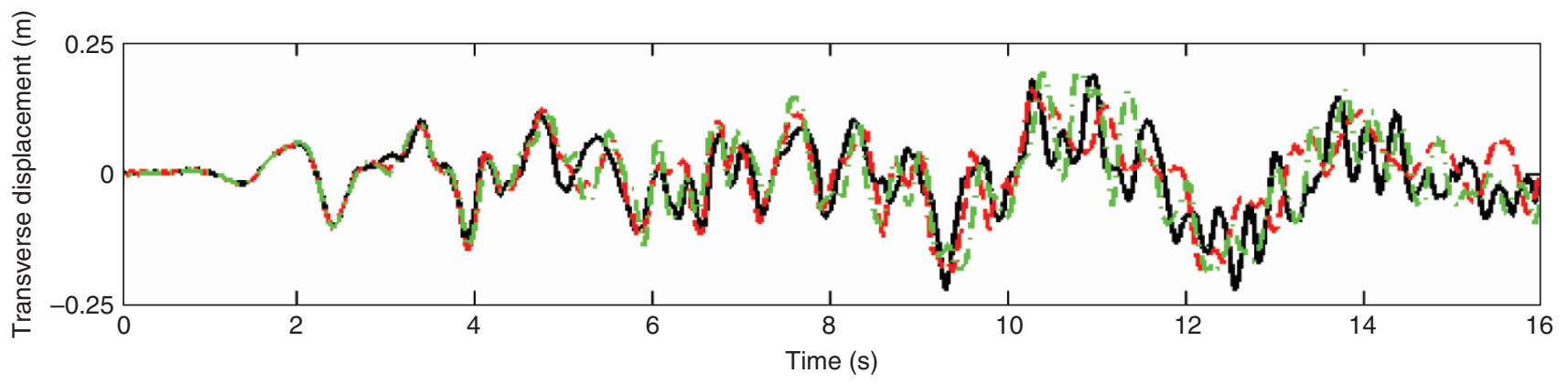

(b) Node 2

Figure 15. Influence of coherency loss on the transverse displacement response

mean peak responses in these two directions. It also can be seen from Figures 16-18 that more high frequency contents are involved in responses in the vertical direction as compared to those in the longitudinal and transverse directions. This is because the stiffness of the bridge in the vertical direction is much higher than that in the longitudinal and transverse directions. For the considered bridge model, the first vertical vibration mode is the $7^{\text {th }}$ mode and the vibration frequency is $2.237 \mathrm{~Hz}$. It should be noted that the lateral side stoppers are not considered in this study. If the stoppers are considered, the transverse responses might be altered. 


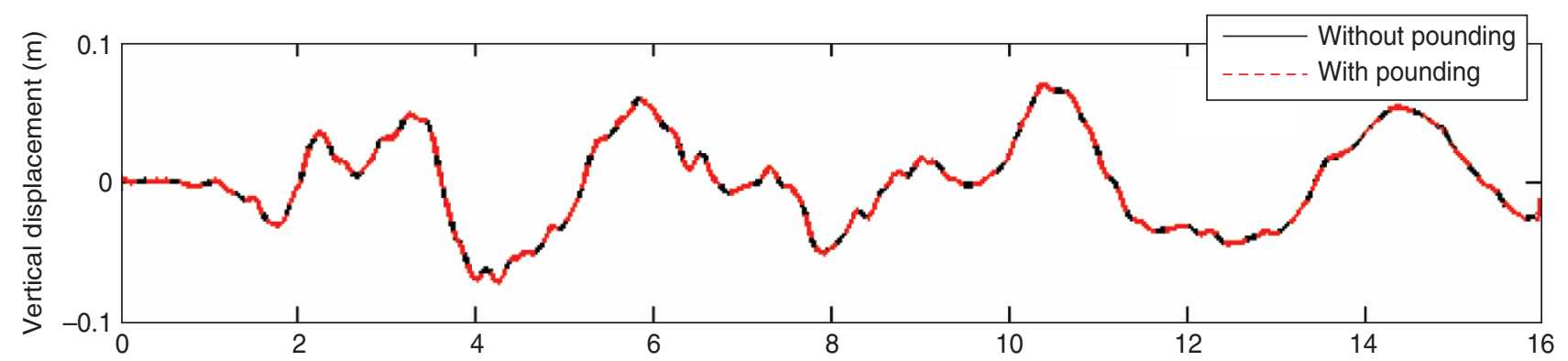

(a) Node 1

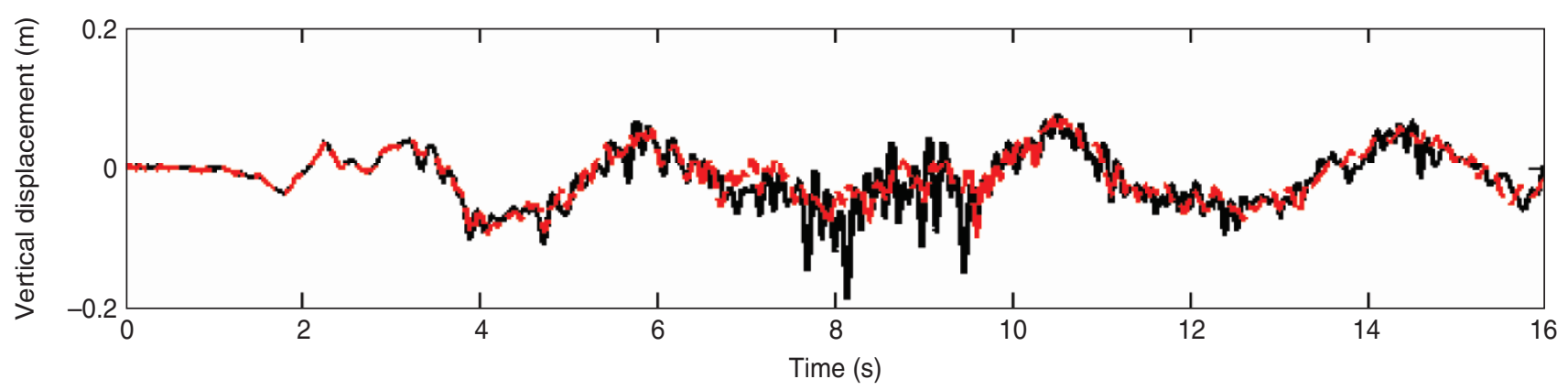

(b) Node 2

Figure 16. Influence of pounding on the vertical displacement response

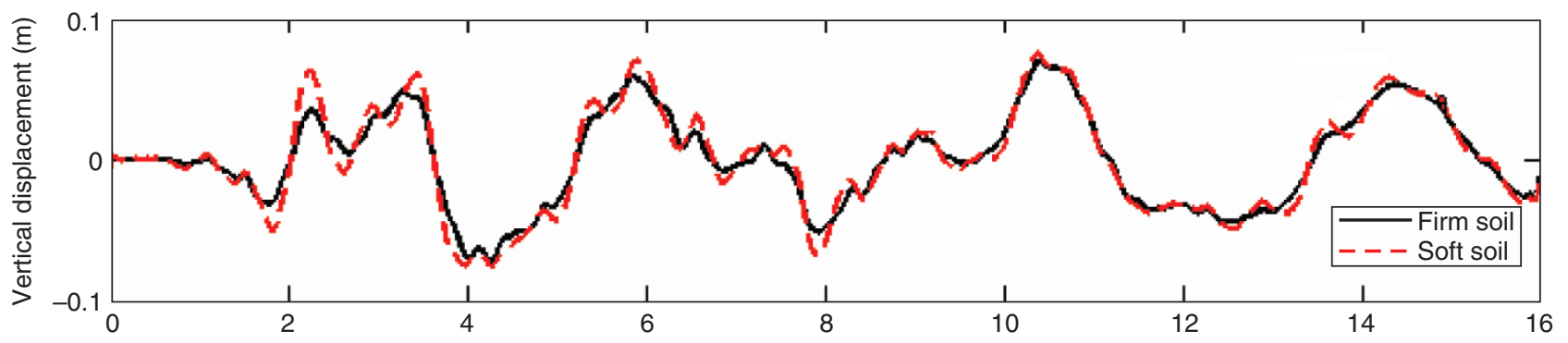

(a) Node 1

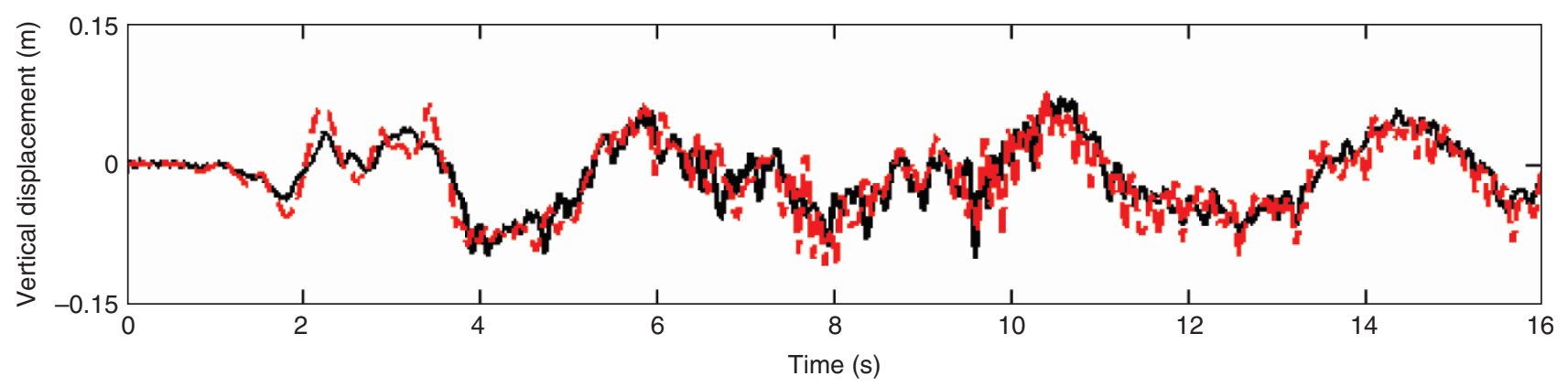

(b) Node 2

Figure 17. Influence of soil conditions on the vertical displacement response

\subsection{Torsional Response}

With the lumped mass model or beam-column element model, the torsional response of the structure cannot be considered because they are $2 \mathrm{D}$ models. With the detailed 3D finite element model, the torsional responses can be estimated by the rotational angle of the corresponding nodes on both sides of the same section, i.e., between nodes 1 and 3, nodes 2 and 4, etc. These can be achieved by dividing the relative longitudinal displacement at these corresponding nodes by the deck width, which is $8.1 \mathrm{~m}$ in the considered case. Table 6 shows the mean peak rotational angles for different 


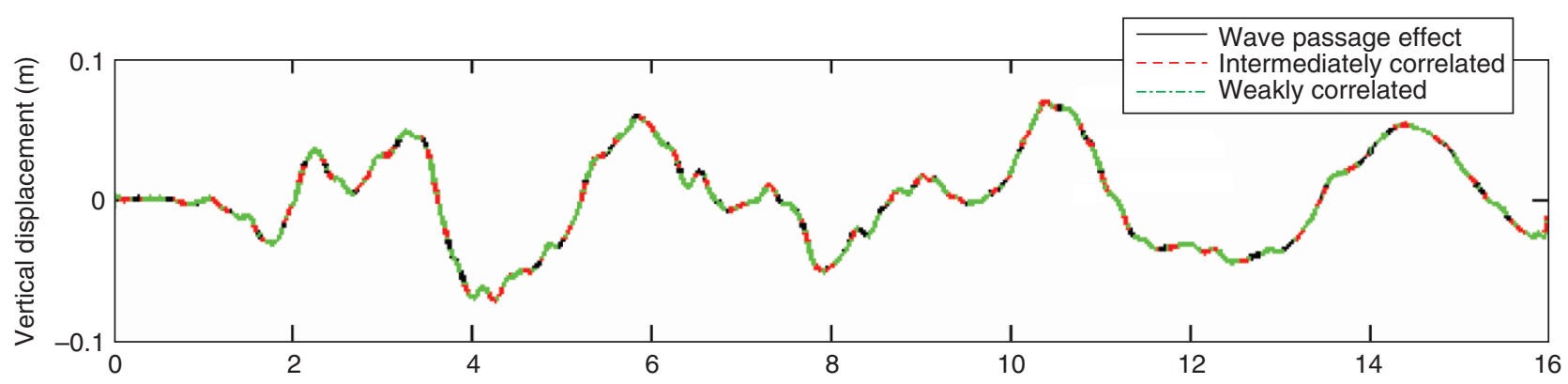

(a) Node 1

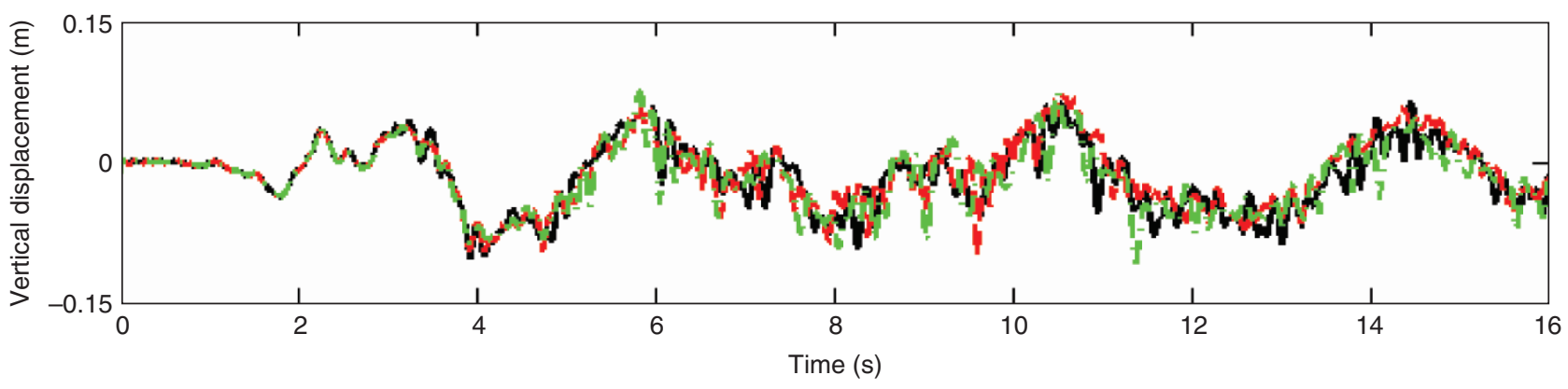

(b) Node 2

Figure 18. Influence of coherency loss on the vertical displacement response

Table 4. Mean peak displacements in the transverse direction $(\mathrm{m})$

\begin{tabular}{lccccc}
\hline & \multicolumn{5}{c}{ Case } \\
\cline { 2 - 6 } Node & $\mathbf{1}$ & $\mathbf{2}$ & $\mathbf{3}$ & $\mathbf{4}$ & $\mathbf{5}$ \\
\hline 1 & 0.119 & 0.119 & 0.202 & 0.119 & 0.119 \\
2 & 0.186 & 0.183 & 0.265 & 0.191 & 0.188 \\
3 & 0.119 & 0.119 & 0.202 & 0.119 & 0.119 \\
4 & 0.185 & 0.182 & 0.265 & 0.189 & 0.187 \\
5 & 0.270 & 0.252 & 0.349 & 0.259 & 0.274 \\
6 & 0.272 & 0.230 & 0.342 & 0.264 & 0.271 \\
7 & 0.270 & 0.252 & 0.348 & 0.259 & 0.272 \\
8 & 0.272 & 0.230 & 0.341 & 0.263 & 0.271 \\
9 & 0.192 & 0.189 & 0.289 & 0.192 & 0.201 \\
10 & 0.123 & 0.123 & 0.196 & 0.119 & 0.125 \\
11 & 0.191 & 0.189 & 0.289 & 0.190 & 0.199 \\
12 & 0.123 & 0.123 & 0.196 & 0.119 & 0.125 \\
\hline
\end{tabular}

cases. Different from the longitudinal, transverse and vertical displacement responses, poundings increase the torsional responses. This is because a longitudinal pounding imposes a restraint to the bridge spans, thus reduces lateral responses. However, eccentric poundings induced by spatially varying ground motions generate large eccentric impact forces that enhance the torsional responses. Comparing Case 3 with Case 2, it is obvious that softer soil results in larger torsional responses. Comparing the responses obtained from
Table 5. Mean peak displacements in the vertical direction (m)

\begin{tabular}{lccccc}
\hline & \multicolumn{5}{c}{ Case } \\
\cline { 2 - 6 } Node & $\mathbf{1}$ & $\mathbf{2}$ & $\mathbf{3}$ & $\mathbf{4}$ & $\mathbf{5}$ \\
\hline 1 & 0.072 & 0.072 & 0.079 & 0.072 & 0.072 \\
2 & 0.162 & 0.111 & 0.131 & 0.116 & 0.114 \\
3 & 0.072 & 0.072 & 0.080 & 0.072 & 0.072 \\
4 & 0.145 & 0.117 & 0.136 & 0.118 & 0.119 \\
5 & 0.152 & 0.106 & 0.127 & 0.118 & 0.117 \\
6 & 0.127 & 0.115 & 0.129 & 0.115 & 0.121 \\
7 & 0.131 & 0.112 & 0.142 & 0.117 & 0.121 \\
8 & 0.131 & 0.121 & 0.130 & 0.116 & 0.132 \\
9 & 0.132 & 0.109 & 0.118 & 0.108 & 0.122 \\
10 & 0.073 & 0.073 & 0.081 & 0.073 & 0.073 \\
11 & 0.125 & 0.110 & 0.121 & 0.105 & 0.119 \\
12 & 0.073 & 0.073 & 0.081 & 0.073 & 0.072 \\
\hline
\end{tabular}

Table 6. Mean peak rotational angle (unit: degree)

\begin{tabular}{lccccc}
\hline & \multicolumn{5}{c}{ Case } \\
\cline { 2 - 6 } Node & $\mathbf{1}$ & $\mathbf{2}$ & $\mathbf{3}$ & $\mathbf{4}$ & $\mathbf{5}$ \\
\hline 1 and 3 & 0.0014 & 0.0177 & 0.0219 & 0.0262 & 0.0149 \\
2 and 4 & 0.2638 & 0.2957 & 0.3459 & 0.2745 & 0.3027 \\
5 and 7 & 0.2150 & 0.2504 & 0.3374 & 0.2879 & 0.2844 \\
6 and 8 & 0.2271 & 0.2624 & 0.3317 & 0.2214 & 0.2766 \\
9 and 11 & 0.2624 & 0.3211 & 0.3572 & 0.2822 & 0.2872 \\
10 and 12 & 0.0007 & 0.0170 & 0.0198 & 0.0113 & 0.0127 \\
\hline
\end{tabular}




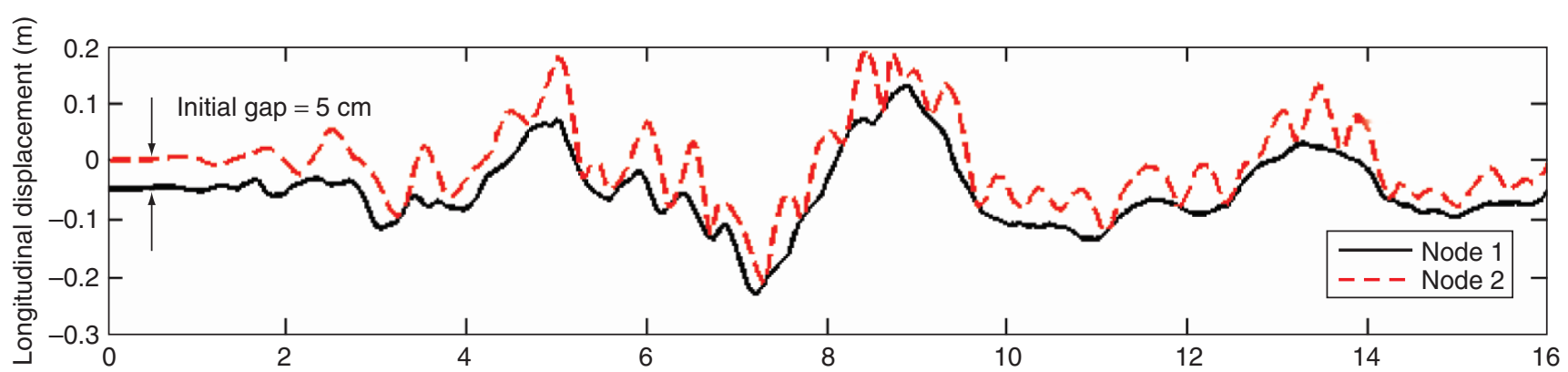

(a) Nodes 1 and 2

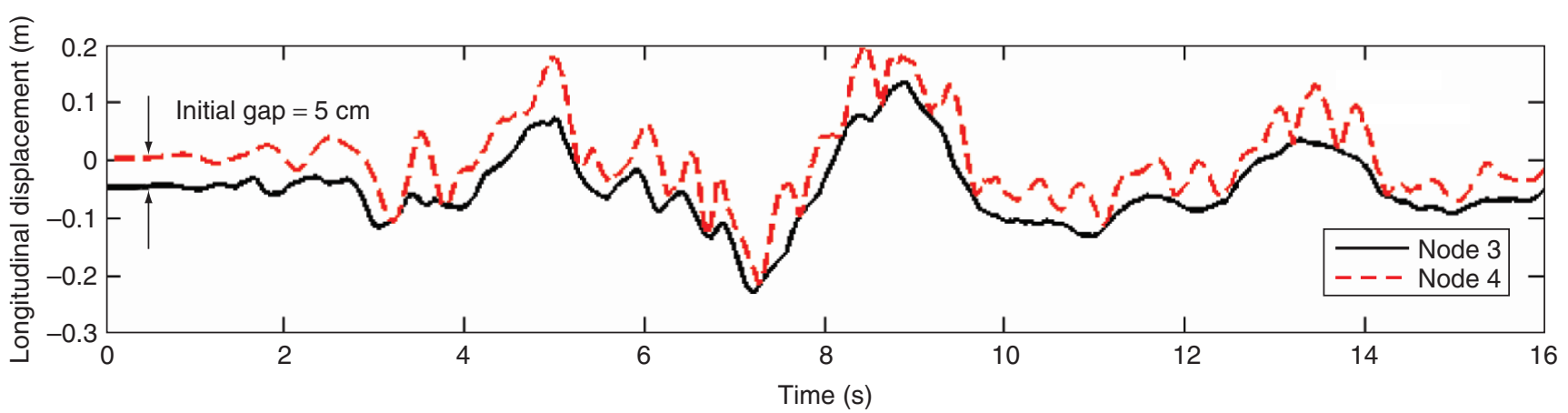

(b) Nodes 3 and 4

Figure 19. Longitudinal displacements at the adjacent nodes due to case 2 ground motions

spatial ground motions with different coherency losses, it is difficult to draw a general conclusion. Although highly correlated ground motions usually lead to the largest longitudinal displacements as discussed in Section 5.1, they do not necessarily yield the largest torsional response. This is probably because the torsional response is related to the relative displacement between nodes on the same cross section of the bridge structure rather than to the absolute displacement.

To examine the occurrence of poundings, the longitudinal displacements of nodes 1 and 2 and nodes 3 and 4 are plotted in the same figure with the displacements of nodes 1 and 3 shifted by the initial gap of $5 \mathrm{~cm}$. Thus, in the figure, the instants when the displacements of the two adjacent points coinciding with each other, indicate the occurrence of poundings. As shown in Figure 19(a), nodes 1 and 2 come into contacts 15 times, at the time instants $3.26,5.29,6.29,6.68,7.30$, $7.72,8.20,8.63,9.13,9.66,11.13,11.89,12.44,13.70$ and 14.26s. Whereas between nodes 3 and 4 as shown in Figure 19(b), the poundings at $6.29,11.89$ and $12.44 \mathrm{~s}$ do not occur, but two more collisions can be observed at 3.76 and 13.20s. Since these points locate at the opposite corners of the bridge deck cross section, pounding at these points occurring simultaneously implies the entire cross sections are in contact, i.e. surface to surface pounding occurs. Otherwise, they are torsional response induced eccentric poundings. In this example, pounding occurring at $6.29,11.89$ and $12.44 \mathrm{~s}$ are eccentric poundings between nodes 1 and 2 , and those at 3.76 and $13.20 \mathrm{~s}$ are eccentric poundings between nodes 3 and 4 . Torsional response induced eccentric poundings between other corner points shown in Figure 5 are also observed. Owing to page limit, they are not presented here. These observations indicate that if 3D model with tri-axial ground motion inputs are considered, more number of poundings will be observed than lumped mass and 2D beam-column element models because the two latter models cannot describe possible eccentric poundings induced by torsional responses.

\subsection{Resultant Pounding Force}

Resultant pounding force in the longitudinal direction can be obtained by integrating the normal stresses over the entire cross section of the contact surface. Though torsional response induced eccentric poundings may result in the noncollinear impacts on the contact surface, the components of pounding forces in the transverse and vertical directions, which are induced owing to friction forces during contact, are relatively small as compared to the component in the longitudinal direction. In this paper, the influences of site conditions and coherency losses on the resultant pounding forces in the longitudinal direction are discussed. Figures 20 and 21 show the pounding forces corresponding to different ground motion cases. It can be seen from 


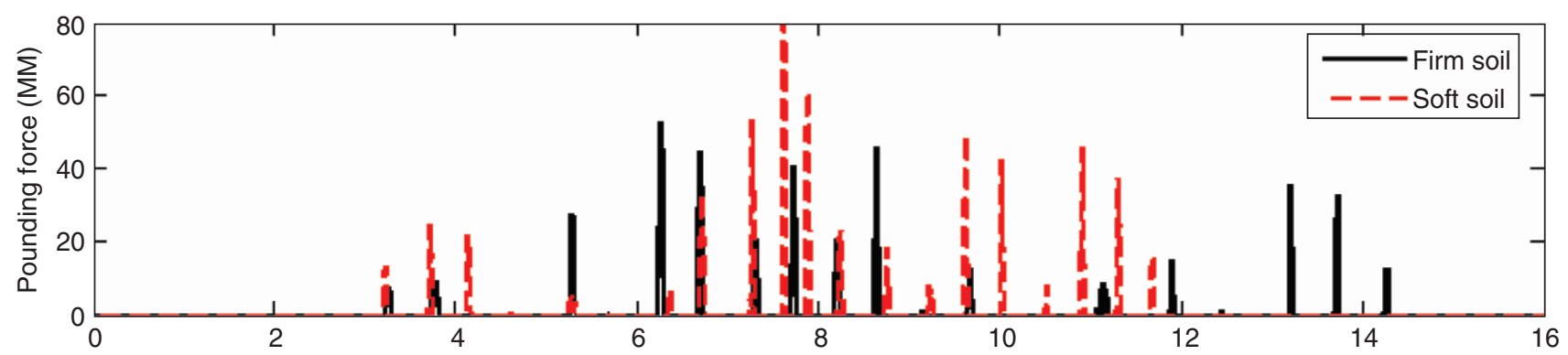

(a) Left gap

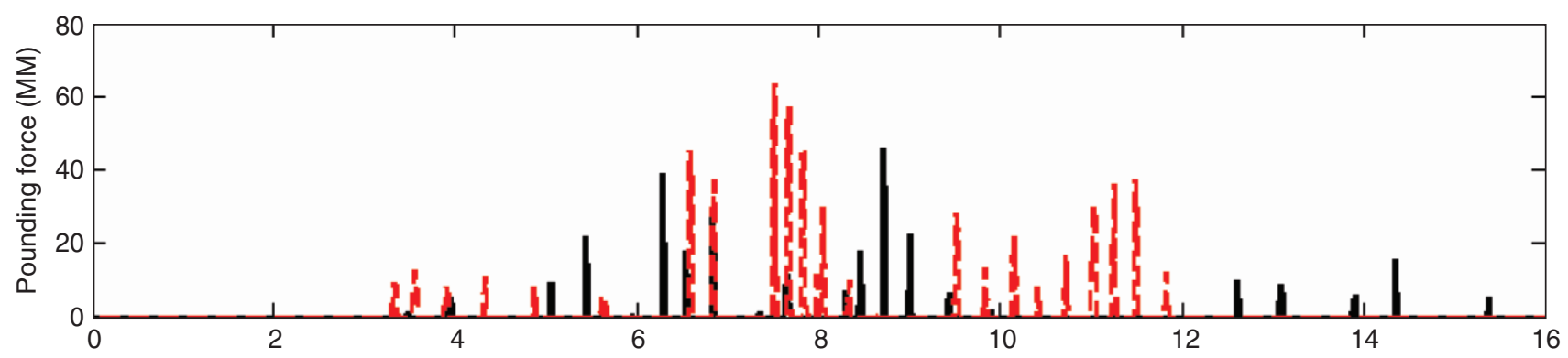

(b) Middle gap

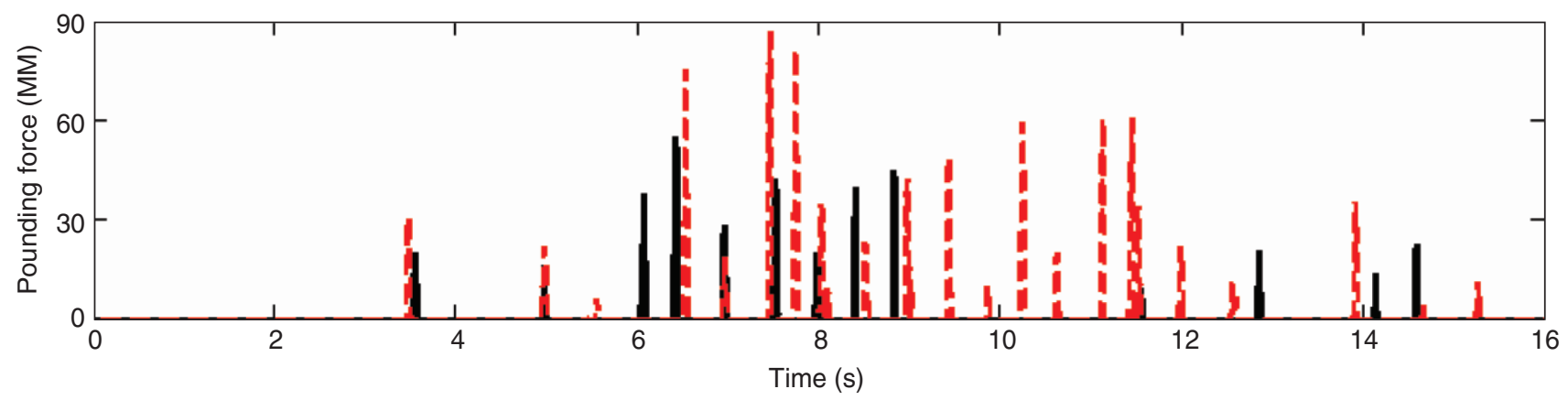

(c) Right gap

Figure 20. Influence of soil conditions on the resultant pounding forces

Figure 20 that soft soil condition results in larger peak pounding forces than firm soil condition. This is because soft soil leads to a larger displacement response in the longitudinal direction as shown in Figure 11, which also results in larger relative displacement between the adjacent components of the bridge and makes the poundings more severe than that on the firm site. Comparing Figures 20(a) and 20(c) with 20(b), it is obvious that the pounding forces between two bridge girders are generally smaller than those between the left or right abutment and the adjacent girder. This is because the bridge analysed in the present study is a symmetric structure, the left and right girders have the same dynamic characteristic and tend to vibrate in phase. If the spatially varying ground motions and the restraints from the abutments are not considered, the two spans will vibrate fully in phase and no pounding will be observed (Hao 1998). At the left and right gaps between abutment and girder, the abutments are much rigid than the adjacent bridge girders, the relative displacement is induced not only by spatially varying ground motions, but also by out of phase vibrations owing to different vibration frequencies of abutment and bridge span. In this case, the out-of-phase vibration induced relative displacement dominates the pounding responses. Therefore, larger pounding forces between abutments and girders are observed. Figure 21 illustrates the consequence of coherency loss between spatial ground motions for the pounding force development. The spatially varying ground motions with wave passage effect only lead to larger pounding forces. This also can be explained by its influence on the longitudinal displacements as shown in Figure 12 and Table 3, where wave passage effect results in larger relative displacement responses. Same conclusion was also drawn in (Chouw and Hao 2008b), in which the two adjacent bridge girders were simplified as two lumped masses. 


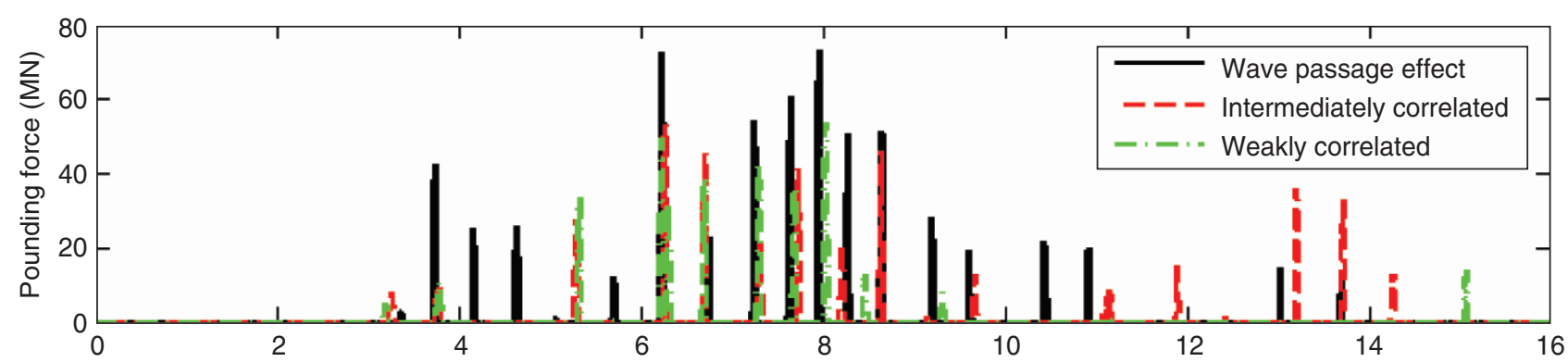

(a) Left gap

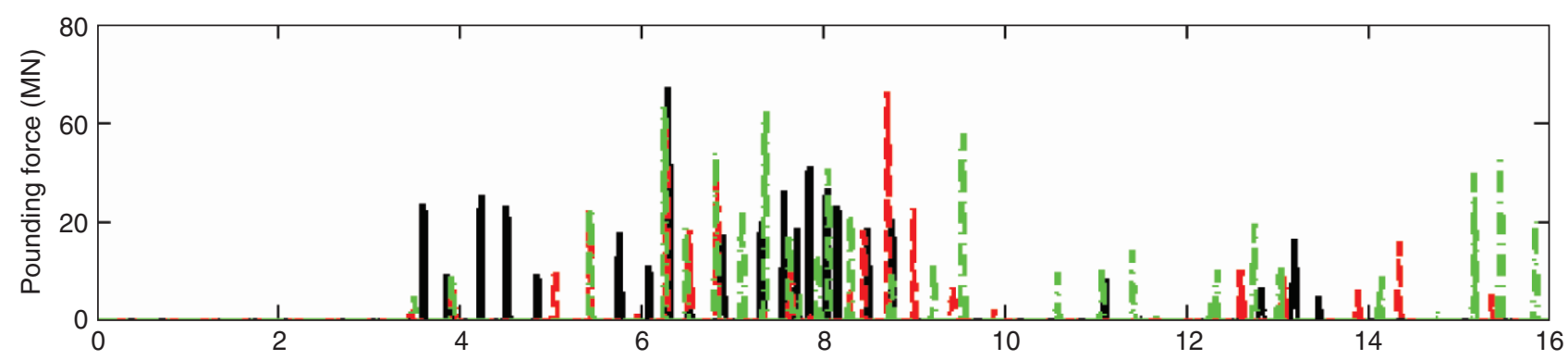

(b) Middle gap

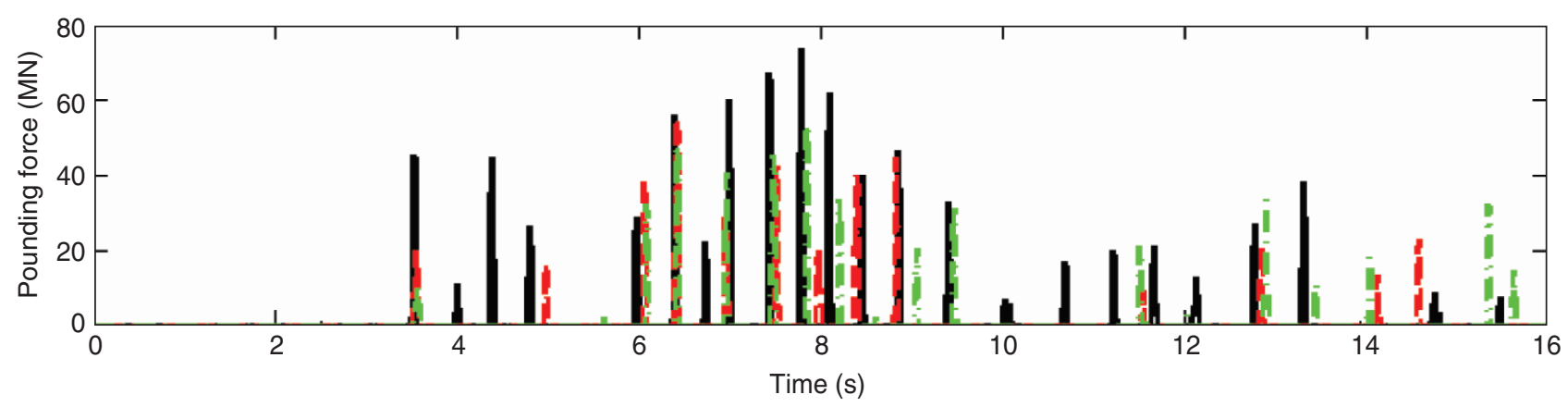

(c) Right gap

Figure 21. Influence of coherency loss on the resultant pounding force

\subsection{Stress Distributions}

By using the traditional lumped mass model or beamcolumn element model, the stress on the entire contact surface will be the same. However, the use of 3D finite element model allows a more detailed prediction of the largest stresses and their locations, and thus enables a more accurate localization of earthquake-induced damage. Figure 22 shows the stress distributions in the longitudinal direction at left expansion joint of the bridge corresponding to the different cases considered in the present study at the time instant when peak resultant pounding force occurs. As shown in Figure 22(a), when bridge is on the firm soil site, the maximum compressive stress appears at the bottom outside corner of the girder. However, when it is on the soft soil site, the maximum compressive stress appears at the top inside corner of the girder. Although surface to surface pounding occurs, the largest stresses always occur at the corners of the bridge girders corresponding to eccentric poundings because the pounding forces are distributed in a smaller area. This is why most observed pounding damages occurred at corners of bridge girders. It also can be seen that larger resultant pounding force not necessarily results in larger compressive stress. Taking the results due to different soil conditions as example, the peak resultant pounding force for firm and soft soil are 55 and $80 \mathrm{MN}$, respectively as shown in Figure 20. The resultant pounding force corresponding to the soft site condition is much larger than that corresponding to the firm site condition. However, the maximum compressive stresses are 88.8 and $59.3 \mathrm{MPa}$, respectively for these two particular pounding events. This is again because the stress development is not only related to the pounding force but also related to the actual contact area at each pounding instant. The lumped mass and beam-column element models, which estimate the stress by dividing the pounding forces by the cross sectional area of the bridge girder, may not lead to correct predictions of 
(a)

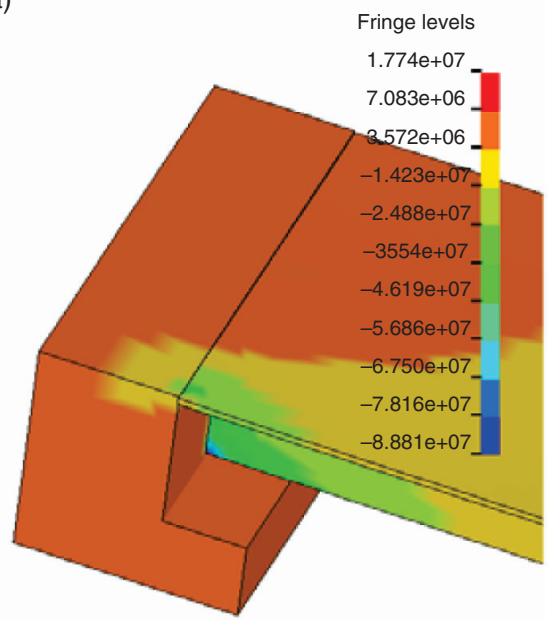

(c)

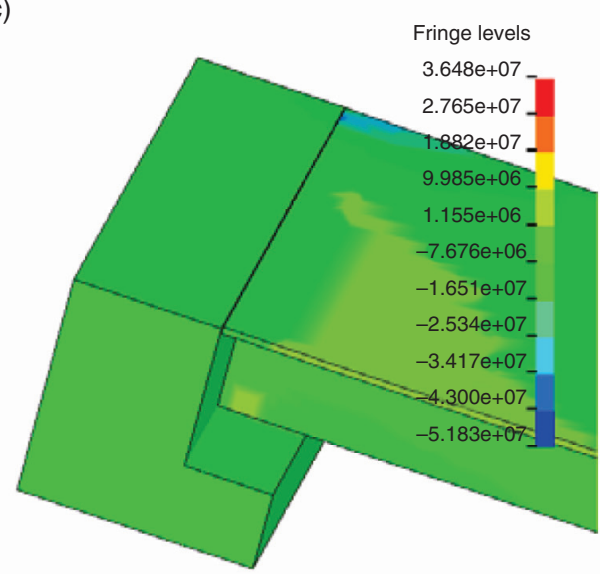

(b)

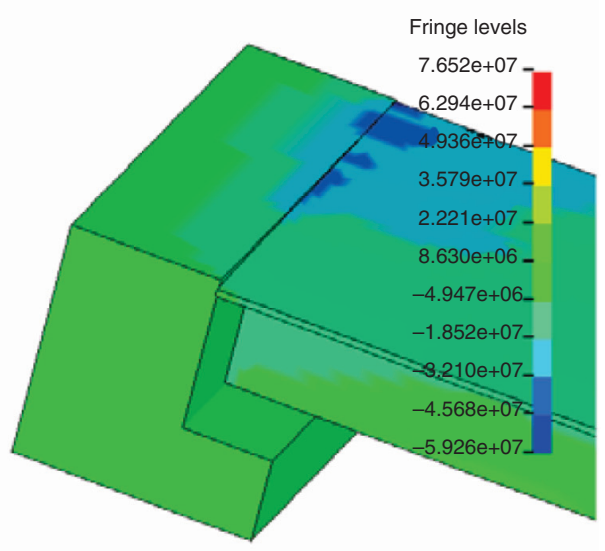

(d)

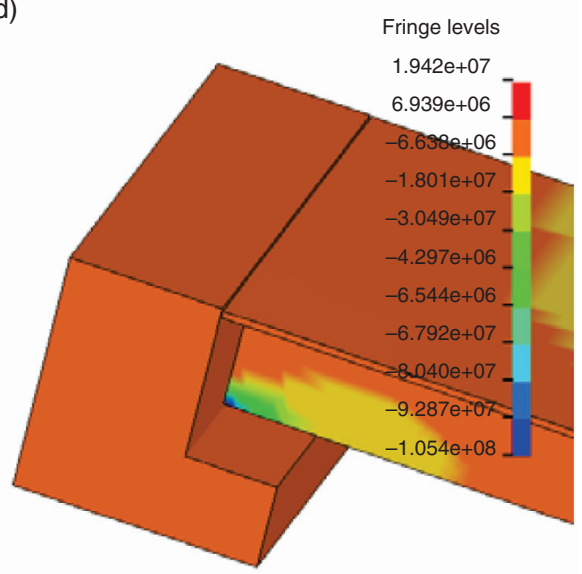

Figure 22. Stress distributions in the longitudinal direction at left expansion joint of the bridge model at the instant when peak resultant pounding force occurs: (a) Case 2; (b) Case 3; (c) Case 4; and (d) Case 5 (unit: Pa)

stresses. As also shown in Figure 22, the maximum stresses can reach as high as 105.4 MPa [Figure 22(d)]. It is much larger than the compressive strength of normal concrete used in bridge construction, which is usually 30-65 MPa under impact loading (Bischoff and Perry 1995), thus concrete damages are expected although the concrete compressive strength increases owing to strain rate effect. These results are consistent with the observations in the past major earthquakes, in which the damages around the corners of the structure were usually the most serious as shown in Figure 1. However, it should be noted that only linear elastic responses are considered in this study. Further study to model concrete damage is necessary as concrete damage will affect the subsequent bridge responses.

\section{CONCLUSION}

Based on a detailed 3D finite element model, the earthquake-induced pounding responses between adjacent components of a two-span simply-supported bridge structure located at a canyon site are studied. The influences of local soil conditions and ground motion spatial variations on the pounding responses are investigated in detail. Following conclusions are obtained:

(1) Lumped mass model and beam-column element model can be used to calculate bridge pounding responses if only longitudinal ground excitation is considered. A detailed 3D finite element model is necessary to describe the torsional response induced by spatially varying transverse ground motions and the corresponding eccentric poundings.

(2) The influence of pounding on the displacement response of the stiff abutments can be neglected. Its influenceon the bridge girder displacement is evident. Poundings usually result in smaller mean peak displacements in the longitudinal, transverse and vertical directions, but larger mean peak torsional responses. 
(3) Local soil conditions significantly influence the structural responses. The softer is the local site, the larger are the structural responses.

(4) Spatially varying ground motions with wave passage effect lead to larger longitudinal displacement. Weakly correlated ground motions result in larger transverse and vertical responses.

(5) Maximum stress appears more likely at the corners of the contact surfaces owing to eccentric poundings.

(6) 3D FE model is needed for more realistic predictions of pounding responses and pounding induced stress concentration and consequently damage to bridge girders.

\section{ACKNOWLEDGEMENT}

The authors acknowledge the partial financial support from ARC Linkage project LP110200906 for carrying out this research.

\section{REFERENCES}

ANSYS (2009). ANSYS User's Manual, Revision 12.1, Canonsburg, Pennsylvania, USA.

Bi, K. and Hao, H. (2011). "Influence of irregular topography and random soil properties on coherency loss of spatial seismic ground motions", Earthquake Engineering and Structural Dynamics, Vol. 40, No. 9, pp. 1045-1061.

Bi, K. and Hao, H. (2012). "Modelling and simulation of spatially varying earthquake ground motions at sites with varying conditions", Probabilistic Engineering Mechanics, Vol. 29, pp. 92-104.

Bi, K., Hao, H. and Chouw, N. (2010a). "Required separation distance between decks and at abutments of a bridge crossing a canyon site to avoid seismic pounding", Earthquake Engineering and Structural Dynamics, Vol. 39, No. 3, pp. 303-323.

Bi, K., Hao, H. and Chouw, N. (2011). "Influence of ground motion spatial variation, site condition and SSI on the required separation distances of bridge structures to avoid seismic pounding", Earthquake Engineering and Structural Dynamics, Vol. 40, No. 9, pp. 1027-1043.

Bi, K., Hao, H. and Ren, W. (2010b). "Response of a frame structure on a canyon site to spatially varying ground motions", Structural Engineering and Mechanics, Vol. 36, No. 1, pp. 111-127.

Bischoff, P.H. and Perry, S.H. (1995). "Impact behaviour of plain concrete loaded in uniaxial compression", Journal of Engineering Mechanics, ASCE, Vol. 121, No. 6, pp. 685-693.

Chouw, N. and Hao, H. (2005). "Study of SSI and non-uniform ground motion effects on pounding between bridge girders", Soil Dynamics and Earthquake Engineering, Vol. 25, No. 7-10, pp. 717-728.

Chouw, N. and Hao, H. (2008a). "Significance of SSI and nonuniform near-fault ground motions in bridge response II: Effect on response with modular expansion joint", Engineering Structures, Vol. 30, No. 1, pp. 154-162.
Chouw, N. and Hao, H. (2008b). "Significance of SSI and nonuniform near-fault ground motions in bridge response I: Effect on response with conventional expansion joint", Engineering Structures, Vol. 30, No. 1, pp. 141-153.

Chouw, N. and Hao, H. (2011). "Pounding behaviour of adjacent structures in the 2011 Christchurch earthquake", Australia Earthquake Engineering Society Conference, Novotel Barossa Valley Resort, South Australia, Australia.

Chouw, N., Hao, H. and Su, H. (2006). "Multi-sided pounding response of bridge structures with non-linear bearings to spatially varying ground excitation", Advances in Structural Engineering, Vol. 9, No. 1, pp. 55-66.

Der Kiureghian, A. (1980). "Structural response to stationary excitation", Journal of the Engineering Mechanics Division, ASCE, Vol. 106, No. 6, pp. 1195-1213.

Der Kiureghian, A. (1996). "A coherency model for spatially varying ground motions", Earthquake Engineering and Structural Dynamics, Vol. 25, No. 1, pp. 99-111.

DesRoches, R. and Muthukumar, S. (2002). "Effect of pounding and restrainers on seismic response of multi-frame bridges", Journal of Structural Engineering, ASCE, Vol. 128, No. 7, pp. 860-869.

Earthquake Engineering Research Institute (1999). Chi-Chi, Taiwan, Earthquake Reconnaissance Report, EERI Report No. 01-02, Oakland, CA, USA.

Hao, H. (1998). "A parametric study of the required seating length for bridge decks during earthquake", Earthquake Engineering and Structural Dynamics, Vol. 27, No. 1, pp. 91-103.

Hao, H. and Ma, G. (1999). "An investigation of the coupled torsional-pounding responses of adjacent asymmetric structures", Proceeding of the $7^{\text {th }}$ East Asian-Pacafic Conference on the Structural Engineering and Constructuion, Kochi, Japan, pp. 788-793.

Hao, H., Oliveira, C.S. and Penzien, J. (1989). "Multiple-station ground motion processing and simulation based on SMART-1 array data", Nuclear Engineering and Design, Vol. 111, No. 3, pp. 293-310.

Jankowski, R. (2009). "Non-linear FEM analysis of earthquakeinduced pounding between the main building and the stairway tower of the Olive View Hospital", Engineering Structures, Vol. 31, No. 8, pp. 1851-1864.

Jankowski, R., Wilde, K. and Fujino, Y. (1998). "Pounding of superstructure segments in isolated elevated bridge during earthquakes", Earthquake Engineering and Structural Dynamics, Vol. 27, No. 5, pp. 487-502.

Jankowski, R., Wilde, K. and Fujino, Y. (2000). "Reduction of pounding effects in elevated bridges during earthquakes", Earthquake Engineering and Structural Dynamics, Vol. 29, No. 2, pp. 195-212.

Jennings, P.C. (1971). Engineering Features of the San Fernando Earthquake of February 9, 1971, EERL Report No.71-02, Earthquake Engineering Research Laboratory, California Institute of Technology, California, USA. 
Julian, F.D.R., Hayashikawa, T. and Obata, T. (2006). "Seismic performance of isolated curved steel viaducts equipped with deck unseating prevention cable restrainers", Journal of Constructional Steel Research, Vol. 63, No. 2, pp. 237-253.

Kawashima, K. and Unjoh, S. (1996). "Impact of Hanshin/Awaji earthquake on seismic design and seismic strengthening of highway bridges", Structural Engineering/Earthquake Engineering, Vol. 13, No. 2, pp. 211-240.

Lin, C.J., Hung, H., Liu, Y. and Chai, J. (2008). "Reconnaissance report of 0512 China Wenchuan earthquake on bridges", The $14^{\text {th }}$ World Conference on Earthquake Engineering, Beijing, China.

LS-DYNA (2007). LS-DYNA User Manual, Livermore Software Technology Corporation, California, USA.

Malhotra, P.K. (1998). "Dynamics of seismic pounding at expansion joints of concrete bridges", Journal of Engineering Mechanics, ASCE, Vol. 124, No. 7, pp. 794-802.

Maragakis, E., Douglas, B. and Vrontinos, S. (1991). "Classical formulations of the impact between bridge deck and abutments during strong earthquake", Proceedings of the $6^{\text {th }}$ Canadian Conference on Earthquake Engineering, Toronto, Canada, pp. 205-212.

Priestley, M.J.N., Seible, F. and Calvi, G.M. (1996). Seismic Design and Retrofit of Bridges, John Wiley \& Sons, New York, USA.

Ruangrassamee, A. and Kawashima, K. (2001). "Relative displacement response spectra with pounding effect", Earthquake Engineering and Structural Dynamics, Vol. 30, No. 10, pp. 1511-1538.

Sobczky, K. (1991). Stochastic Wave Propagation, Kluwer Academic Publishers, Netherlands.

Tajimi, H. (1960). "A statistical method of determining the maximum response of a building structure during an earthquake", Proceedings of $2^{\text {nd }}$ World Conference on Earthquake Engineering, Tokyo, Japan, pp. 781-796.

Wolf, J.P. (1985). Dynamic Soil-Structure Interaction, Prentice Hall, Englewood Cliffs, New Jersey, USA.

Zanardo, G., Hao, H. and Modena, C. (2002). "Seismic response of multi-span simply supported bridges to spatially varying earthquake ground motion", Earthquake Engineering and Structural Dynamics, Vol. 31, No. 6, pp. 1325-1345.
Zhu, P., Abe, M. and Fujino, Y. (2002). "Modelling threedimensional non-linear seismic performance of elevated bridges with emphasis on pounding of girders", Earthquake Engineering and Structural Dynamics, Vol. 31, No. 11, pp. 1891-1913.

\section{NOTATION}

$L_{s} \quad$ bridge length of the short span

$m_{s} \quad$ mass of the short span

$k_{s} \quad$ pier stiffness of the short span

$\xi_{s} \quad$ damping ratio of the short span

$f_{s} \quad$ vibration frequency of the short span

$L_{l} \quad$ bridge length of the long span

$m_{l} \quad$ mass of the long span

$k_{l} \quad$ pier stiffness of the long span

$\xi_{l} \quad$ damping ratio of the long span

$f_{l} \quad$ vibration frequency of the long span

$E \quad$ Young's modulus of bridge deck and piers

$\rho \quad$ density of bridge deck and piers

$h \quad$ height of bridge piers

$k_{p} \quad$ stiffness of impact element

$c_{p} \quad$ damping of impact element

$\xi_{p} \quad$ damping ratio of impact element

$e \quad$ coefficient of restitution

$\omega_{f} \quad$ central frequency of high pass filter

$\xi_{f} \quad$ damping ratio of high pass filter

$\omega_{g} \quad$ central frequency of Tajimi-Kanai power spectral density function

$\xi_{g} \quad$ damping ratio of Tajimi-Kanai power spectral density function

$\Gamma \quad$ scale factor depending on the ground motion intensity

$\gamma_{j^{\prime} k^{\prime}},(i \omega)$ coherency loss function between the ground motions at points $j^{\prime}$ and $k^{\prime}$

$d_{j^{\prime} k^{\prime}} \quad$ projected distance between points $j^{\prime}$ and $k^{\prime}$ in the wave propagation direction

$\alpha \quad$ incident angle of incoming wave to the soil site

$\beta$ coefficient depending on the level of coherency loss

$v_{a p p} \quad$ apparent wave velocity on the base rock

$T$ duration of simulated time history 